\title{
TIME TO CONCEIVE - A NEW ARGUMENT FOR THE POSSIBILITY OF TIME TRAVEL
}

\author{
By
}

Daniel Burkett

\begin{abstract}
A thesis
submitted to the Victoria University of Wellington

in fulfilment of the requirements for the degree of

Master of Arts

in Philosophy
\end{abstract}

Victoria University of Wellington 



\section{Abstract}

Ordinarily, philosophers arguing for the possibility of time travel restrict themselves to defending time travel against allegations of inconsistency and contradiction. These objections are usually based on particular theories about time and causality. I believe, however, that this way of arguing can be turned on its head. By using the conceivability thesis - that is, the thesis that if something is conceivable, then it is also possible - we can put forward a positive argument for the possibility of time travel, and then consider how this should inform our metaphysical views.

I do this by assuming the truth of the conceivability thesis and then presenting a simple piece of time travel fiction. I argue for the conceivability of this story and, in doing so, attempt to show that the time travel journey it describes is logically possible. I then develop this argument by considering other more controversial cases of time travel. I make minor alterations to the original time travel story in order to show that there are a number of different kinds of time travel journeys (including cases of both forwards and backwards time travel) which are conceivable and, therefore, logically possible.

Finally, I ask how the conceivability of different types of time travel should affect the metaphysical views we choose to adopt. I argue that since the conceivability of time travel entails the logical possibility of journeys to other times, any plausible theory of time must be able to accommodate such journeys. I also explain how the conceivability of time travel entails the logical possibility of two particularly unusual cases of causation. I argue that the conceivability of instantaneous time travel entails the logical possibility of causation at a distance, and that the conceivability of backwards time travel entails the logical possibility of backwards causation. Any plausible theory of causation must therefore be able to account for the possibility of these two types of causation. I consider one particular theory of causation which does not (namely, that put forward by D.H. Mellor), and then attempt to establish where it goes wrong. 


\section{Acknowledgements}

My sincerest gratitude goes to: Mum, Dad and Lisa Seddon for all of their love and support throughout the writing process; Simon Keller for his invaluable teaching and tremendously helpful feedback; Ken Perszyk and Cei Maslen for teaching me everything I know about time travel; John Bigelow and Paul Daniels for their helpful suggestions at the 2012 Australasian Association of Philosophy Annual Conference; David Gilbert, Gareth Leniston-Lee, Justin Ngai, and Dan Weijers for helping me to understand a myriad of metaphysical concepts more clearly; Ryan Kerr for being my philosophical sounding-board for the better part of seven years; Finn O'Keefe for keeping me inspired with exclamations of "I don't believe it!"; and Daniel Ryan for rescuing this manuscript from the clutches of a dying hard drive on more than one occasion. 


\section{Table of Contents}

Chapter 1: Conceiving of a Time Travel Journey .........................................................

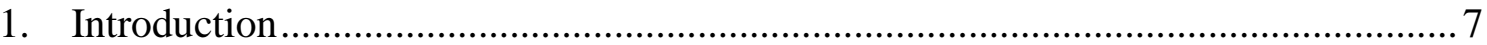

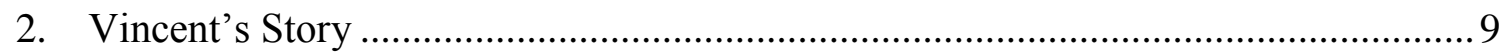

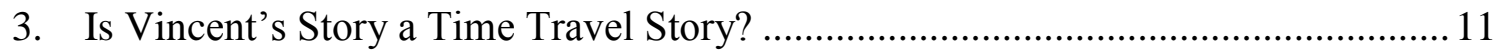

4. Is Vincent's Story a Conceivable Time Travel Story? ............................................ 12

4.1 Prima Facie versus Ideal Conceivability ................................................... 14

4.2 Positive versus Negative Conceivability .................................................. 15

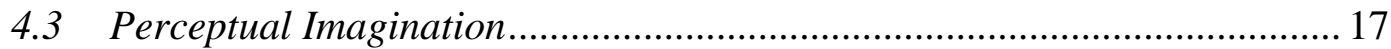

4.4 Coherent Modal Imagination ................................................................ 18

5. Coherently Imagining a Possible World in Which Vincent's Story Takes Place..... 20

5.1 Immersing Ourselves in the Narrative .................................................... 20

5.2 Filling in Further Facts.................................................................... 22

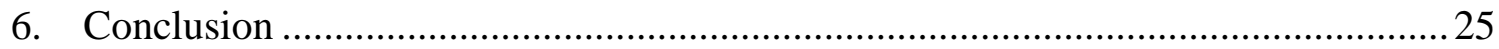

Chapter 2: Conceiving of Other Time Travel Journeys - Forwards Time Travel...... 27

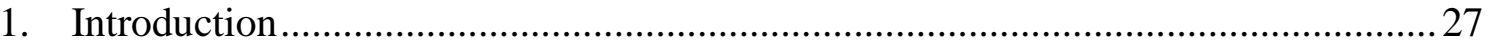

2. Distinguishing Between Different Kinds of Time Travel Journeys ........................2 27

2.1 Distinguishing Time Travel Journeys by Direction .................................. 28

2.2 Distinguishing Time Travel Journeys by Duration .................................... 28

2.3 Different Kinds of Time Travel............................................................. 29

3. Conceiving of Instantaneous Forwards Time Travel Journeys................................29

4. Conceiving of Gradual Forwards Time Travel Journeys......................................... 32

4.1 Journeying Forwards Outside of Time and Space .................................... 34

4.2 Journeying Forwards Through Time and Space ....................................... 36

4.3 Re-evaluating ‘Genuine’ Time Travel........................................................ 38

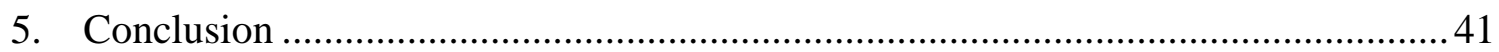

Chapter 3: Conceiving of Other Time Travel Journeys - Backwards Time Travel ... 42

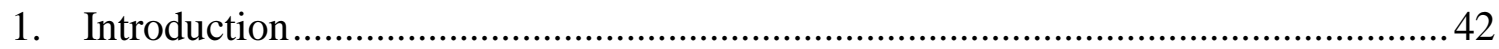

2. Sidestepping the Usual Objections to the Possibility of Backwards Time Travel ... 42

3. Conceiving of Instantaneous Backwards Time Travel Journeys .............................. 44

4. Conceiving of Gradual Backwards Time Travel Journeys ..................................... 48 
4.1 Journeying Backwards Outside of Time and Space ...................................50

4.2 Journeying Backwards Through Time and Space .................................... 51

4.3 Gradual Backwards Time Travel and the Double Occupancy Problem...... 52

4.4 Dowe's Solution to the Double Occupancy Problem .................................... 54

4.5 An Alternative Solution to the Double Occupancy Problem ........................ 56

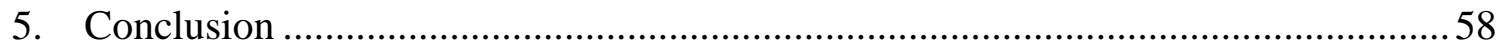

Chapter 4 - Presentism and the Conceivability of Time Travel ........................................ 60

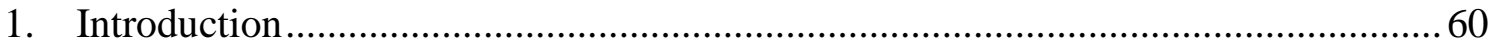

2. How the Conceivability Thesis Informs Our Metaphysical Views ...........................60

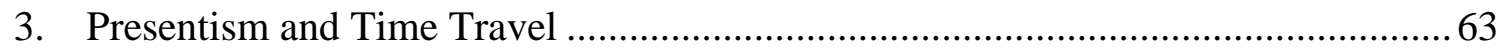

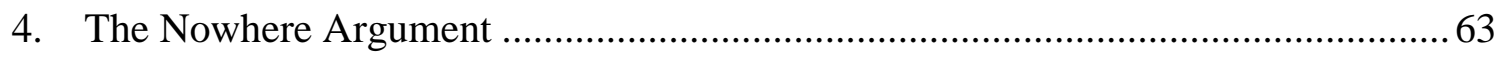

5. The Conceivability of Time Travel and the Somewhere Argument ........................65

6. Possible Presentist Replies to the Somewhere Argument.........................................6 66

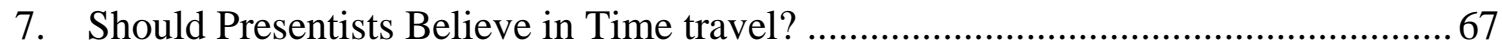

7.1 Keller and Nelson's Criticism of the Nowhere Argument........................... 68

7.2 Travelling to Non-existent Times ................................................................... 68

7.3 Presentist Time Travel and Personal Identity ........................................... 71

7.4 Presentist Time Travel as Suicide ............................................................... 73

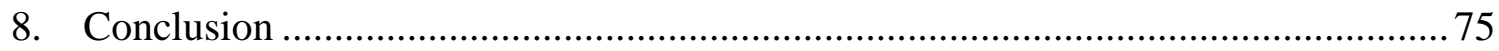

Chapter 5: Causation and the Conceivability of Time Travel............................................ 76

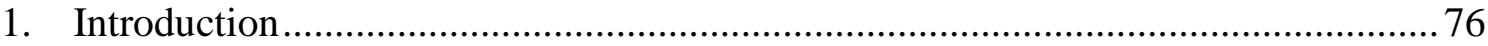

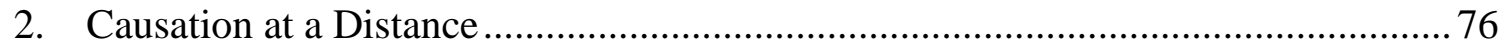

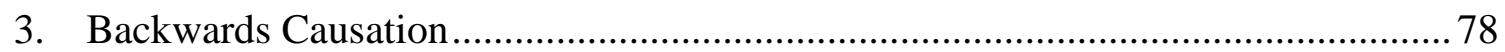

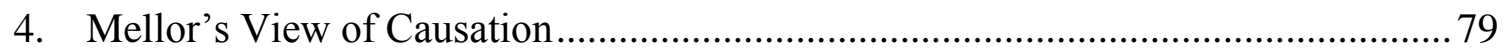

5. Backwards Causation on Mellor's View of Causation ............................................. 81

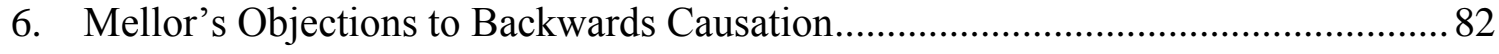

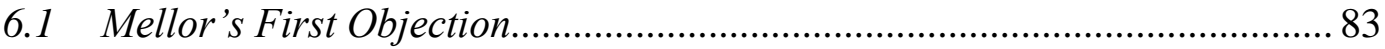

6.2 Responding to Mellor's First Objection................................................... 85

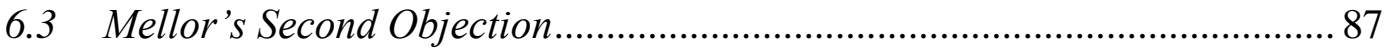

6.4 Responding to Mellor's Second Objection ............................................... 92

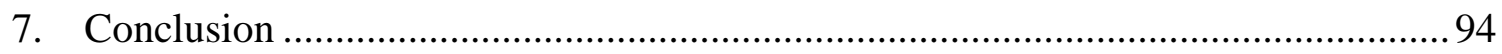

Chapter 6: Final Conclusion ...............................................................................96

Bibliography ......................................................................................................................................99 


\section{Chapter 1: Conceiving of a Time Travel Journey}

\section{Introduction}

Time travel is possible. While some time travel stories may be incoherent, this only demonstrates the impossibility of certain cases of time travel. In this thesis I will argue that there is nothing essentially inconsistent about time travel journeys.

Ordinarily, philosophers arguing against the logical possibility of time travel do so by making specific allegations of contradictions. These arguments tend to follow a very similar structure. Firstly, they outline something that time travel supposedly allows us to do. Secondly, they describe how this particular thing is logically impossible. The Time Discrepancy Objection, for example, states that time travel allows for time discrepancies to occur, but that such discrepancies are logically impossible. Suppose that thirty-year-old Vincent travels ten years into the past. If this is possible, then it would be possible for Vincent to be thirty years old only twenty years after the date of his birth. This, however, seems contradictory. The Two-Places-at-Once Objection, on the other hand, states that time travel is impossible because it allows someone to be in two places at once (say, by allowing thirty-year-old Vincent to go and shake hands with his twenty-year-old self), but that this state of affairs is also contradictory.

These kinds of arguments are easily refuted, and Ken Perszyk and Nicholas J.J. Smith have already provided an excellent summary of how we might go about doing this. ${ }^{1}$ Further, in 'The Paradoxes of Time Travel' ${ }^{2}$ David Lewis provides a defense against one of the strongest arguments against the possibility of time travel - the infamous Grandfather Paradox..$^{3}$

\footnotetext{
${ }^{1}$ Ken Perszyk and Nicholas J.J. Smith, The Paradoxes of Time Travel, presented at Te Papa (National Museum of New Zealand) on 23 August 2001.

${ }^{2}$ David Lewis, 'The Paradoxes of Time Travel', Philosophical Papers Volume II (Oxford University Press, 1987), pp. 67-80.

${ }^{3}$ This is the paradox which arises from a story in which a time traveller goes to the past and attempts to kill his or her own grandfather. A minor variation on this is the Auto-Infanticide Paradox, where the time traveller attempts to kill his or her younger self.
} 
A much stronger argument against the possibility of time travel is that it is essentially inconsistent. An argument of this kind is usually based upon the claim that all time travel stories necessarily contain a contradiction. John Bigelow raises this objection in 'Time Travel Fiction'. ${ }^{4}$ He argues that time travel stories require a "deep spatialization of time", 5 but that such a view of time is incoherent. In this thesis I will attempt to refute the claim that time travel is essentially inconsistent. I will not attempt to reply to Bigelow's specific argument, but will instead put forward my own positive argument for the logical possibility of some cases of time travel. If successful, this argument will preclude any potential claim that time travel is essentially inconsistent, regardless of how that objection is made.

In The Conscious Mind ${ }^{6}$ David Chalmers argues for the possibility of psychological zombies by using the conceivability thesis. This is the thesis that if something is conceivable, then that thing must also be logically possible. I believe a similar argument can be made for the possibility of time travel. In order to do this, I will analyse the conceivability of time travel by looking at fictional stories. I will argue that some time travel stories are conceivable, and that the conceivability of these stories provides good evidence for the logical possibility of the time travel journeys they describe.

In Chapter 1 of this thesis I will argue for the conceivability of one particular case of time travel - namely, an instance of instantaneous forwards time travel. In Chapters 2 and $3 \mathrm{I}$ will expand this argument by demonstrating the conceivability of several other cases of time travel. In doing so, I will show that there are many time travel journeys (including cases of both forwards and backwards time travel) that are perfectly conceivable and, therefore, logically possible.

In Chapter 4 I will discuss what implications the conceivability of time travel has for our view of time. In 'No Time Travel for Presentists', ${ }^{7}$ Steven D. Hales puts forward

\footnotetext{
${ }^{4}$ John Bigelow, 'Time Travel Fiction' in Gerhard Preyer \& Frank Siebelt (eds.), Reality and Humean Supervenience: Essays on the Philosophy of David Lewis (Rowman \& Littlefield Publishers, 2001), pp. 5791.

${ }^{5}$ Ibid., p. 57.

${ }^{6}$ David Chalmers, The Conscious Mind: In Search of a Fundamental Theory (New York: Oxford University Press, 1996), pp. 93-99.

${ }^{7}$ Steven D. Hales, 'No Time Travel for Presentists', Logos \& Episteme I, 2 (2010), pp. 353-360.
} 
the familiar argument that presentism is incompatible with time travel. If this is correct, then presentists must hold that there is no possible world in which time travel occurs. If my argument is successful however, it will show that there is time travel in some possible world irrespective of what any contrary metaphysical theory might say. I will argue that presentism must either be made to accommodate the logical possibility of time travel (something which Simon Keller and Michael Nelson have already attempted to do) ${ }^{8}$ or abandoned altogether.

Finally, in Chapter 5 I will discuss what implications the conceivability of time travel has for our view of causality. In Real Time II, ${ }^{9}$ D. H. Mellor outlines a theory of causation which holds causation at a distance and backwards causation to be logical impossibilities. The conceivability of certain cases of time travel, however, allows us to conceive of these very types of causation. I will consider what this means for Mellor's view of causation.

I will conclude that many cases of time travel are conceivable, and therefore logically possible. This possibility precludes any argument that time travel is essentially inconsistent. Not only this, but it also has serious ramifications for any metaphysical theory which holds time travel as a logical impossibility.

\title{
2. Vincent's Story
}

Consider the following story:

\begin{abstract}
Vincent has built a time machine. Vincent steps into the machine at $12.00 \mathrm{pm}$ on Wednesday $1^{\text {st }}$ January 2020 . He sets the destination time on the machine's control panel to “6.00pm Wednesday $1^{\text {st }}$ January 2020" and presses the 'On' button. The machine disappears. At 6.00pm that same day the machine reappears. The physical processes going on within Vincent and the time machine are now exactly as they would have been immediately after Vincent pressed the 'On' button at $12.00 \mathrm{pm}$ if he had not in fact pressed the button. Vincent exits the time machine (conveniently located in his garage) and goes
\end{abstract}

\footnotetext{
${ }^{8}$ Simon Keller and Michael Nelson, 'Presentists Should Believe in Time Travel', Australasian Journal of Philosophy, Vol. 79, No. 3 (September 2001), pp. 333-345.

${ }^{9}$ D.H. Mellor, Real Time II (London: Routledge, 1988).
} 
into his living room. Once there, he makes a cup of tea and turns on the television to watch the six o'clock news.

I believe that this story is conceivable, and that its conceivability provides good evidence for the logical possibility of the time travel journey it describes. In order to make this argument we must show that (1) Vincent's story is a time travel story, (2) Vincent's story is a conceivable time travel story, and (3) the conceivability of Vincent's story implies its logical possibility.

For the purposes of this paper I will assume that (3) is true. In 'Does Conceivability Entail Possibility?' David Chalmers puts forward a persuasive argument for the connection between conceivability and logical possibility. ${ }^{10}$ It is clear that we cannot properly conceive of something which is logically impossible ${ }^{11}$ - we cannot, for example, conceive of a married bachelor or a three-sided square. The conceivability thesis builds upon this observation, stating that if we can properly conceive of something then that thing must be logically possible. As Paul Tidman notes, the significance of the conceivability thesis is that "if true, it promises to provide an independent epistemological means by which we can determine what is possible." 12

If the conceivability thesis is true, then the way in which we can clearly imagine, explain, and reason about some time travel stories provides us with good evidence for the logical possibility of the time travel journeys they describe. Thus, if Vincent's particular story is conceivable, then Vincent's story will also be possible.

I will now consider (1) and (2) in turn.

${ }^{10}$ David Chalmers, 'Does Conceivability Entail Possibility' in T. Gendler \& J. Hawthorne (eds), Conceivability and Possibility (Oxford University Press, 2002), pp. 145-200.

${ }^{11}$ Exactly what it means to 'properly' conceive of something is a topic I will soon turn to.

${ }^{12}$ Paul Tidman, 'Conceivability as a Test for Possibility', American Philosophical Quarterly, Vol. 31, No. 4 (October 1994), p. 298. 


\section{Is Vincent's Story a Time Travel Story?}

Is Vincent's story a time travel story? It certainly resembles many of those stories that we call 'time travel stories', but mere resemblance is not enough. Some stories describe series of events which seem to be time travel but which, on closer inspection, turn out to be something else entirely. Certain facts must be present in Vincent's story in order for it to contain a genuine case of time travel.

Firstly, a genuine time travel journey must involve travel to the actual past or future - not some replica of it. ${ }^{13}$ Visiting the set of a period film or going to a medieval fair does not count as time travel, nor does travelling to an alternate universe which merely looks like the past or future of our own universe. Vincent's journey satisfies this requirement. He has not arrived in some futuristic facade replete with actors and clocks secretly running 6 hours fast, nor has he travelled to the future of some other universe. When Vincent steps out of his time machine he finds himself at the 'real' $6.00 \mathrm{pm}$ on Wednesday $1^{\text {st }}$ January 2020.

Secondly, a genuine time traveller must be able to physically interact with the time to which he travels. ${ }^{14}$ Merely having visions of the past or future (as does A Christmas Carol's Ebenezer Scrooge) is not sufficient. Vincent's journey satisfies this requirement too, as evidenced by his ability to exit his machine and interact with his surroundings.

Finally, and perhaps most importantly, a genuine time travel journey requires a discrepancy between the period of time travelled and the duration of the journey. ${ }^{15}$ The period of time travelled (hereafter referred to as $p$ ) is the difference in time between the time traveller's point of departure and his destination. If Vincent time travels from $12.00 \mathrm{pm}$ to $6.00 \mathrm{pm}$, then $p$ will be 6 hours. The duration of the journey (hereafter referred to as $d$ ) is the period of time the time traveller experiences while travelling from his point of departure to his destination. If Vincent experiences the journey as being instantaneous, then $d$ will be 0 . In order for a time travel journey to be genuine, $p$ cannot equal $d$. Vincent's journey meets this requirement as $p$ is 6 hours while $d$ is 0 .

\footnotetext{
${ }^{13}$ Perszyk and Smith, op. cit., p. 1.

${ }^{14}$ Ibid., p. 2.

${ }^{15}$ Ibid.. See also Lewis (1987), op. cit., p. 67.
} 
Vincent's story therefore contains the necessary requirements for a genuine case of time travel.

\section{Is Vincent's Story a Conceivable Time Travel Story?}

Is Vincent's story conceivable? It certainly seems to be, at least on some intuitive notion of conceivability. We understand the facts of the story, and understanding these facts does not require us to deal with any obvious contradictions. We understand the idea of a man whose name is Vincent. We understand disappearances, reappearances and the passage of time in the ordinary way. We can even understand the idea of a time machine and what it is meant to be capable of doing (even if we do not understand precisely how it does it).

But understanding these particular facts is not the same as conceiving of the story which contains them. If our test for conceivability were only this rigorous, then we would find that many time travel stories are 'conceivable' - including some stories which turn out to be logically impossible. Consider Marty McFly's journey in Back to the Future. ${ }^{16}$ Marty travels from 1985 to 1955 and jeopardises his own conception by inadvertently preventing his parents from meeting for the first time. The facts of this story may be understandable, but the time travel journey it describes is contradictory. Marty's experience is a classic case of the second-time-around fallacy: that is, the mistaken idea that something can both happen and not happen at the very same time. Marty's parents either meet in 1955, or they do not. It cannot be the case that both of these scenarios occur. Despite this, the time travel story presented in Back to the Future seems to suggest that they do.

The second-time-around fallacy is often avoided by assuming that the time traveller does something other than travelling to the actual past. Perhaps Marty does travel back in time, but also skips to a parallel timeline in which his meddling in the past can be accommodated without contradiction. Thus Marty does not travel to 1955, but rather $1955^{*}$; an alternate 1955 where he is free to interfere with his parents' meeting. When

\footnotetext{
${ }^{16}$ Back to the Future, Dir. Robert Zemeckis, Universal Pictures, 1985.
} 
Marty travels back to 1985 he is in fact returning to $1985^{*}$, the future of $1955^{*}$. On this interpretation Marty's journey would appear as follows:

1955

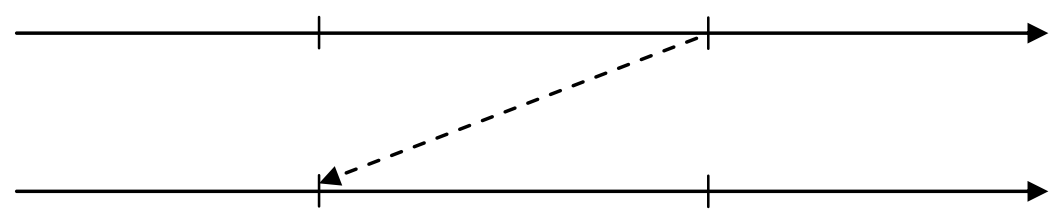

$1955^{*}$

$1985^{*}$

There are two problems with this interpretation. Firstly, if Marty skips timelines, then interfering with the meeting of his parents in $1955^{*}$ could in no way affect the meeting of his parents in the timeline from which he originates. Despite this, Marty's slow fading from existence in the final act of the film seems to show that Marty has clearly affected the history of his own timeline. ${ }^{17}$ Secondly, if Marty had skipped timelines, then his journey would fail to meet the first requirement of a genuine time travel journey: that is, that the time traveller travels to the actual past or future. Marty's story would be logically possible, but would no longer be a time travel story.

Back to the Future is a logically impossible time travel story. If we maintain the facts required to ensure Marty's journey is a genuine time travel journey, then we are faced with an unavoidable contradiction. Since we cannot conceive of a contradiction, it must be the case that our initial conception of Back to the Future was flawed.

\footnotetext{
${ }^{17}$ There are other problems with the parallel-timeline interpretation of Marty's journey. Upon 'returning' to $1985^{*}$ Marty is reunited with his family and girlfriend. But these are not the same loved ones he left behind in 1985. They are completely different people with different histories and personalities; people with whom Marty shares no common memories. What's more, 1985* was already inhabited by a Marty (let's call him Marty*). Marty arrives in $1985^{*}$ just in time to see Marty* travel back in time. What is to become of that individual? Does Marty* also travel back to $1955^{*}$, or has he too skipped timelines and travelled to an entirely new $1955^{* *}$ ? And what of Marty's family in 1985 ? For them Marty has simply vanished, never to return again.
} 


\subsection{Prima Facie versus Ideal Conceivability}

David Chalmers highlights this problem by drawing a distinction between 'prima facie' and 'ideal' conceivability. ${ }^{18}$ This distinction describes the rigour with which we must analyse the conceivability of a story. According to Chalmers, something will be prima facie conceivable when that thing "is conceivable... on first appearances". ${ }^{19}$ Vincent's story meets this requirement, but then so does Back to the Future. ${ }^{20}$ The problem with prima facie conceivability is that it is an imperfect guide to possibility. ${ }^{21}$ Some stories (such as that in Back to the Future) are conceivable on first appearances, but do not remain conceivable on further analysis. As Chalmers notes: ${ }^{22}$

It sometimes happens that [something] is prima facie conceivable... but that this prima facie conceivability is undermined by further reflection showing that the tests that are criteria for conceivability are not in fact passed. In this case, [that thing] is not ideally conceivable.

In this way, something which is prima facie conceivable can be shown to be inconceivable on further reflection. This will usually be done by "isolating a contradiction or a misdescription in an apparently conceivable state of affairs". ${ }^{23}$ When a prima facie conceivability judgement is undermined, so too are any grounds that the conceivability judgement provides for a claim of possibility. ${ }^{24}$ For this reason, Vincent's story needs to be ideally conceivable. Something will be ideally conceivable where it "is conceivable... on ideal rational reflection". ${ }^{25}$

What is meant by 'ideal rational reflection'? According to Chalmers, "one could try to define ideal conceivability in terms of the capacities of the ideal reasoner - a reasoner free from all contingent cognitive limitations". ${ }^{26}$ The only difficulty with this approach is that it is possible that for every ideal reasoner, there is a more sophisticated ideal

\footnotetext{
${ }^{18}$ Chalmers (2002), op. cit., p. 147.

${ }^{19}$ Ibid.

${ }^{20}$ A story which leads to an unavoidable contradiction (assuming we wish to keep those facts which make it a time travel story in the first place).

${ }^{21}$ Chalmers (2002), op. cit., p. 159.

${ }^{22}$ Ibid., p. 147.

23 Ibid.

${ }^{24}$ Ibid.

${ }^{25}$ Ibid (emphasis added).

${ }^{26}$ Ibid., p. 148 (emphasis added).
} 
reasoner. ${ }^{27}$ Alternatively, one might adopt a notion of indefeasibility. That is, in order for something to be ideally conceivable, there must be justification for the conceivability "that cannot be rationally defeated". ${ }^{28}$ While this approach would provide us with an exceptionally reliable test for conceivability, it runs into great difficulties in its application. How are we to know whether or not our justifications are indefeasible? Some things might seem indefeasibly conceivable, despite there being some possible (though as yet undiscovered) defeasor in existence.

It is true that we can never know for certain whether or not we are 'ideally' conceiving of some situation, however Chalmers does not think that proof of the indefeasibility of each case of ideal conceivability is required. Instead, he argues that by using the term 'indefeasible' he is "simply appealing to our intuitive grasp of notions of reasoning and of when one reasoning process defeats another". ${ }^{29}$ He notes that the concept of indefeasibility is often employed in epistemological statements and that for this reason claims of conceivability are no worse-off than claims of knowledge.

The sceptic, however, will still believe that our inability to have any certainty regarding ideal conceivability should lead us to be sceptical about the possibility of time travel. I disagree. We have not set out to provide irrefutable proof of the ideal conceivability of some time travel stories. Instead, it should be sufficient to give very good reasons for believing that these stories are conceivable (and therefore possible). While we may not have certainty regarding our ability to conceive ideally of time travel fictions, the fact that we seem so sure of it provides good evidence for their possibility.

\subsection{Positive versus Negative Conceivability}

In order to conceive ideally of Vincent's story, we must do more than just understand the facts that are described to us. We must be able to reflect rationally on those facts and their relationship with one another. According to Chalmers, we can conceive of something in either of two ways: negatively, or positively. Something will be negatively

\footnotetext{
${ }^{27}$ Ibid.

${ }^{28}$ Ibid.

${ }^{29}$ Ibid.
} 
conceivable when that thing "is not ruled out a priori" $" 30$ and positively conceivable when "one can form some sort of positive conception of a situation in which [that thing] is the case. ${ }^{31}$ Put simply, to say that something is negatively conceivable is to say that "as far as we know, $\mathrm{X}$ is conceivable". To say that something is positively conceivable is to say that "X is conceivable".

In this way, something may be negatively conceivable even where some (as yet undiscovered) contradiction exists. Positive conceivability, on the other hand, ensures that no contradiction exists by forcing us to imagine those facts which would allow that thing to be the case. ${ }^{32}$ For this reason, the positive conceivability of Vincent's story would provide us with a much stronger argument for the logical possibility of time travel than would its negative conceivability. This follows Chalmer's view that both "ideal positive conceivability and ideal negative conceivability are promising as guides to possibility", ${ }^{33}$ but that "due to its added strength, the former is in a slightly better position to be a perfect guide than the latter". 34

What will count as a positive conception of Vincent's story? According to Chalmers, imagination is the key: ${ }^{35}$

It is common to imagine situations in considerable detail, and this imagination is often accompanied by interpretation and reasoning. When one imagines a situation and reasons about it, the object of one's imagination is often revealed as a situation in which [that thing] is the case.

There are, however, two different ways in which we might imagine the time travel journey described in Vincent's story.

\footnotetext{
${ }^{30}$ Ibid, p. 149.

${ }^{31}$ Ibid, p. 150

${ }^{32}$ This distinction should sound familiar. Negatively conceiving of some state of affairs is analogous to the way in which we argue for the possibility of travel by refuting allegations of inconsistency. In both cases we attempt to show that something is not ruled out. In neither case, however, do we prove that it could not be ruled out.

${ }^{33}$ Ibid. p. 161.

${ }^{34}$ Ibid.

${ }^{35}$ Ibid, p. 150.
} 


\subsection{Perceptual Imagination}

The most common way to imagine something is to conjure up a mental image of that thing. This is what Chalmers refers to as 'perceptual imagination'. ${ }^{36}$ Perceptually imagining something is different from merely 'supposing' or 'entertaining' that that same thing is the case. ${ }^{37}$ When we suppose or entertain a particular proposition $P$, we adopt a certain attitude towards that proposition. Usually this just requires us to stipulate that $P$ is true. Perceptual imagination, on the other hand, "involves an attitude not just toward $P$, but toward some specific situation that stands in a certain relationship to $P^{338}$ - that is, a situation that makes $P$ true. This 'situation' is the mental image which contains the thing we are attempting to conceive of. The process of perceptual imagination is described well by Paul Tidman, who states that: ${ }^{39}$

\footnotetext{
In order to tell whether a state of affairs is possible... we should... attempt to form a mental image of the state of affairs. If we succeed in doing so, that suffices to show that the state of affairs is possible.
}

Consider an example. If we were asked to suppose or entertain the proposition that "there is a working perpetual motion machine" we would merely need to stipulate this as true. If we were instead asked to imagine perceptually that "there is a working perpetual motion machine" we would be required to adopt an attitude regarding some situation which, if real, would make that statement true. Perhaps we would imagine switching on such a machine, watching it run, and watching it continue to run indefinitely with no new power input whatsoever.

Vincent's story describes a situation that, if real, would make time travel possible. We can perceptually imagine Vincent's garage and the events that occur within on that fateful Wednesday afternoon. We can picture Vincent stepping into the machine, setting his destination, and pressing the 'On' button. We can picture the machine disappearing and then reappearing six hours later. We can even picture Vincent emerging from the machine

\footnotetext{
${ }^{36}$ Ibid.

${ }^{37}$ Ibid.

${ }^{38}$ Ibid.

${ }^{39}$ Tidman, op. cit., p. 298.
} 
having experienced nothing of the previous six hours. If perceptual imagination is what we mean by conceivability, then we are quite capable of conceiving of Vincent's story.

Is perceptual imagination the right test for conceivability however? It is clear that perceptual imagination is not necessary for possibility, as there are many possible things that we cannot perceptually imagine. ${ }^{40}$ This is not fatal to the argument above however. All that is required is that perceptual imagination is sufficient for possibility. But is this the case? It appears not. Evidence for this can be found in the fact that we seem to be quite capable of forming mental images of states of affairs which involve contradictions. Consider the works of M. C. Escher, many of which contain visual representations of impossible situations (see specifically Ascending and Descending, Belvedere, and Waterfall). ${ }^{41}$ Likewise, we can form a mental image of the story presented to us in Back to the Future, despite the fact that this story is impossible. As Tidman notes, it seems that we can form a mental image of almost any state of affairs whatsoever, ${ }^{42}$ and that this should "preclude drawing any conclusions concerning the possibility of the state of affairs from the mere fact that you can form a mental image purporting to picture it". ${ }^{43}$

Perceptual imagination is not enough for conceivability. In order for the conceivability thesis to work, we must establish that we are imagining the right sort of image in order for us to be able to draw conclusions regarding possibility. ${ }^{44}$ This requires us to establish a way of distinguishing "mental images from which it is safe to infer possibility from those from which it is not". 45

\subsection{Coherent Modal Imagination}

Ideally conceiving of something requires more than just conjuring up a mental image of that thing. A more reliable method of imagining might be coherent modal

\footnotetext{
${ }^{40}$ Ibid. Tidman's examples include God's being omnipotent, our possessing invisible souls, $2+2$ 's equalling 4 , and gold's having an atomic number of 79 .

${ }^{41}$ I am indebted to John Bigelow for inspiring the use of Escher's works as examples in this discussion.

${ }^{42}$ Tidman, op. cit., p. 299.

${ }^{43}$ Ibid.

${ }^{44}$ Ibid.

${ }^{45}$ Ibid.
} 
imagination: that is, imagining a possible world in which something is the case. More formally, a person will use coherent modal imagination to imagine something when he or she "imagines a world... or a situation that verifies [that thing]" 46 and where further "reflection" 47 and "reasoning" 48 about the imagined situation confirms it as a situation in which that thing is the case.

Let us return to the example of the perpetual motion machine. In order to perceptually imagine this device we merely needed to conjure up a mental image of its operation. If we are to use coherent modal imagination however, we must imagine a much larger set of facts - that is, the set of facts which also explains how the machine operates. I might picture the components of the machine (say, a battery-powered motor which uses a dynamo to harness the kinetic energy of the motor to recharge its own batteries), the operation of the components (power flows from the batteries to the motor, the motor runs, the dynamo is turned, and power flows back to the batteries), and how the laws of nature must operate in a world in which such a machine works. It is in our attempts to imagine these facts that any underlying contradictions would become apparent.

This seems to be exactly what we should expect from a test for possibility. To say that something is logically impossible is to say that there is no possible world in which that thing is the case. If we are capable of imagining a possible world in which that thing is the case (and we are doing so coherently), then it cannot be true that such a thing is logically impossible.

The conceivability (and thereby possibility) of Vincent's time travel story depends on our ability to imagine coherently a possible world in which his journey takes place. In the next section I will argue that we are clearly able to do this.

\footnotetext{
${ }^{46}$ Ibid.

${ }^{47}$ Ibid, p. 152.

${ }^{48}$ Chalmers (2002), op. cit., p. 153.
} 


\section{Coherently Imagining a Possible World in Which Vincent's Story Takes Place}

In order to conceive ideally of Vincent's journey, we must be able to imagine a possible world in which four facts are true:

1. Vincent and his time machine disappear at $12.00 \mathrm{pm}$ on Wednesday $1^{\text {st }}$ January 2020.

2. Vincent and his time machine appear at $6.00 \mathrm{pm}$ on Wednesday $1^{\text {st }}$ January 2020.

3. Upon appearing, Vincent is able to exit his time machine and physically interact with the world around him.

4. Upon appearing, Vincent's immediately prior experience is of having pressed the 'On' button in his time machine at $12.00 \mathrm{pm}$ on Wednesday $1^{\text {st }}$ January 2020.

Coherently imagining a possible world in which Vincent's story takes place requires more than just imagining these facts however. We must also be able to reflect on and reason about that situation. Indeed, it is the ability to do these things that distinguishes coherent modal imagination (coherently imagining a possible world in which Vincent's story takes place) from mere perceptual imagination (conjuring up a mental image of Vincent's story).

There are two ways in which we can demonstrate our ability to imagine coherently a world in which Vincent's story takes place.

\subsection{Immersing Ourselves in the Narrative}

Firstly, we can imagine coherently a world in which Vincent's story takes place by immersing ourselves in the narrative of that story. Immersion requires more than merely understanding or picturing a story, it also involves engaging with the plot in a meaningful way. Immersion is the practice that allows us to understand a character's motivations and become emotionally invested in their fate. Their concerns become our concerns, and our 
interest in their welfare may even begin to resemble the sort of interest we have in those much closer to us, such as family or friends. Immersion is what happens when we become truly 'caught up' in a story.

Immersion cannot occur where a narrative contains a blatant contradiction. We could not, for example, immerse ourselves in a story which involved a married bachelor, or a character that lived in a square house with only three walls. The sheer absurdity of these situations would prevent the audience from engaging with these plots in any meaningful sort of way.

Can we immerse ourselves in Vincent's story?

I contend that we can. We might have some difficulty understanding Vincent's motivations or becoming emotionally invested in his fate, but this is due to the limited facts of the story. Time travel writers can of course write bad time travel stories, and we cannot discount these stories as inconceivable simply because they are penned by an inept author. Perhaps, then, we should not look at whether we can immerse ourselves in a story, but rather whether that story describes a situation which could be the subject of a narrative in which we can immerse ourselves.

In the case of Vincent's story, any barriers to immersion are created merely by this author's lack of skill at writing good science fiction, not by the fact that the story involves a case of time travel. Once properly fleshed out, the situation described in Vincent's story could easily become the basis of a story in which readers could fully immerse themselves. We might write a new story in which Vincent's journey is the realisation of a childhood dream or a short 'test-flight' preceding a much longer journey into the far future (perhaps in order to discover a remedy for the presently incurable ailment of a loved one). However we might choose to embellish this story, the fact that it is a time travel story will in no way prevent us from immersing ourselves in its narrative.

The potential for us to immerse ourselves in Vincent's story clearly demonstrates our ability to imagine coherently a possible world in which it takes place. This in turn provides good evidence for the conceivability, and thus possibility, of Vincent's journey. 
There is, however, a problem with immersability as a test for conceivability. This is the fact that we seem capable of immersing ourselves in the narratives of stories which are impossible. We have already discussed the clear contradictions in Back to the Future, yet despite this there seems to be nothing stopping us from becoming emotionally involved in Marty's fate or understanding his desperation in wanting to have his parents reunited. It seems that we are just as capable of immersing ourselves in Marty's story as we are in Vincent's.

But are we? I contend that we do not truly immerse ourselves in stories such as Marty's. Instead, we immerse ourselves in these stories by deliberately ignoring certain contradictions. We feign immersion by saying "I won't consider this" or "I'll just pretend this makes sense". This is not necessarily a bad thing. Sometimes this sort of suspension of disbelief is necessary in order to discuss interesting scenarios that we otherwise could not consider. Feigned immersion is not good evidence for the conceivability of a story however. Instead, true immersion is required. This means engaging with a story without any reservations.

\subsection{Filling in Further Facts}

A second way we can imagine coherently a world in which Vincent's story takes place is by filling in extra facts. Chalmers agrees that this is the key to coherent modal imagination, stating that "true coherence requires that arbitrary details can be filled in with no contradiction revealing itself on idealized reflection" ${ }^{49}$ In order for something to be positively conceivable, it must be possible "to flesh out any missing details of an imagined situation that verifies [that thing], such that the details are imagined clearly and distinctly, and such that no contradiction is revealed". 50

A story, then, is like a partially completed connect-the-dots picture. On this analogy, the facts explicitly given to the reader in the story represent those dots that have already been connected. In order to establish whether or not the story is capable of being

\footnotetext{
${ }^{49} \mathrm{Ibid}$

${ }^{50}$ Ibid.
} 
coherently modally imagined, we must connect the remaining dots and see whether or not a consistent picture emerges.

Vincent's story stands up well to this analysis. We can clearly fill in extra facts in his story such that no contradiction reveals itself. We can, for example, fill in facts regarding what happened before his journey (what he had for breakfast and how he prepared for his impending journey). We can also continue his story, filling in facts regarding what happened after the completion of his journey (perhaps he mothballs his time travel project, satisfied that the device works effectively).

Of course, the facts that we will most be expected to fill in are those facts which explain how the time machine works and where it is that Vincent goes between 12.00pm and 6.00pm.

Providing an answer to the latter question is fairly straightforward. Vincent does not 'go' anywhere. One moment he is temporally located at $12.00 \mathrm{pm}$, and the very next moment he is at $6.00 \mathrm{pm}$. If he were to look out the window of his time machine as he pressed the 'On' button, he would see the hands of the clock on his garage wall jump instantaneously from $12.00 \mathrm{pm}$ to $6.00 \mathrm{pm}$. Since Vincent skips over those six hours, he does not need to spend that time anywhere (or anywhen for that matter).

Answering the question of how the time machine works is more challenging. We do not, however, need to give a specific description of how Vincent's time machine works in order to successfully conceive of his story. ${ }^{51} \mathrm{I}$ seem about as capable of explaining the mechanics of a time machine as I do the inner workings of my PC, but that does not prevent me from successfully conceiving of scenarios containing computers. All that we need to do in order to be able to conceive of Vincent's journey is to imagine some possible world in which his journey occurs - a world in which a machine such as that described

\footnotetext{
${ }^{51}$ That is not to say that we could not provide such a description however. Physicists such as Ronald Mallett believe that they have sufficient evidence to describe how time travel can not only occur in some possible world, but even in this actual world. For further discussion of this, see Ronald Mallett and Bruce Henderson, Time Traveller - A Scientist's Personal Mission to Make Time Travel a Reality (New York: Basic Books, 2009).
} 
does, by some contrivance, instantaneously ${ }^{52}$ transport Vincent six hours into the future. The specific mechanics of how this machine works are immaterial.

This may sound suspiciously like the 'faux-immersion' criticised above: that is, a wilful ignorance of certain problems within the story. This is not what we are doing however. Omitting explanatory facts is quite different from turning a blind eye to blatant contradictions. While we may be required to do the former in order to conceive of Vincent's journey, at no time are we required to do the latter.

What facts, then, must be filled out in order for us to imagine coherently a possible world in which Vincent's time travel journey occurs? Vincent must somehow disappear at $12.00 \mathrm{pm}$. Vincent must then also reappear at $6.00 \mathrm{pm}$ having experienced none of the 6 hours between his times of disappearance and appearance. So long as there is a possible world in which these facts hold (as well as those facts demonstrating Vincent's ability to physically interact with the world after his journey is complete), there will be a possible world in which time travel occurs.

Imagining a possible world in which disappearances and reappearances occur should not be difficult. We regularly describe (and make sense of) stories containing disintegrations, apparitions or teletransportation, all of which require the disappearance and/or reappearance of certain things and persons. For this reason, we must be able to imagine coherently possible worlds in which these sorts of things occur. Imagining a possible world that contains the disappearance and reappearance of a man and a time machine should be no different.

Perhaps the disappearance and reappearance of persons over time is different. It may be the case, depending on one's particular view of time, that there is some extra concern regarding the conceivability of a time traveller disappearing now and reappearing later. On some views of time, the future has not happened yet, so the time traveller (apparently) has nowhere to go. This might be a problem that is specific to forwards time travel as in cases of backwards time travel the past is already there and so can be travelled to. This, however, is an objection arising from a confusion regarding how Vincent's story

\footnotetext{
${ }^{52}$ That is, 'instantaneously' from Vincent's perspective.
} 
is told. The above would only be a problem if it was necessary for us to say something like "Vincent just disappeared at $12.00 \mathrm{pm}$ and now is at $6.00 \mathrm{pm}$." This, however, is not the way in which Vincent's story is described. Vincent and his machine disappear at $12.00 \mathrm{pm}$ and are not located anywhere or anywhen for the next six hours. Their journey does not require an already existing future for them to travel to. Instead, they simply reappear when $6.00 \mathrm{pm}$ does arrive. Vincent and his machine avoid the problem outlined above by not arriving in the future until the future is already happening.

\section{Conclusion}

Vincent's story contains a typical case of time travel. We can imagine a possible world in which Vincent's story occurs and reflect on and reason about this world, as evidenced by our ability to immerse ourselves in the narrative and fill in extra facts in the story without any contradiction revealing itself. For this reason, Vincent's story seems capable of coherent modal imagination and is therefore ideally conceivable. If we assume the truth of the conceivability thesis, then the conceivability of Vincent's story also entails its possibility. This shows that at least some time travel journeys are logically possible.

If any of the facts of Vincent's story $d o$ lead to a contradiction, then it is up to the critic of time travel to demonstrate this. Like Chalmers, I believe that the 'obviousness' of what we are describing means that: ${ }^{53}$

\footnotetext{
“...a certain burden of proof lies on those who claim that a given description is logically impossible. If someone truly believes that [something] is logically impossible, she must give us some idea of where a contradiction lies... If no reasonable analysis of the terms in question points toward a contradiction, or even makes the existence of a contradiction plausible, then there is a natural assumption in favour of logical possibility."
}

Many objections to the conceivability of Vincent's journey will highlight problems with conceiving of his story occurring in this world (or some world very close to this world). They do not, however, go so far as to show that we cannot conceive of his story occurring in any possible world. The imagined world in which Vincent's journey occurs

\footnotetext{
${ }^{53}$ Ibid., p. 97
} 
might be subject to physical laws that are very different to those of our own world. It might be a very strange world indeed. However so long as we can conceive of Vincent's journey occurring in some possible world, then it will not be the case that time travel is essentially inconsistent. 


\section{Chapter 2: Conceiving of Other Time Travel Journeys - Forwards Time Travel}

\section{Introduction}

The conceivability thesis can be used to make a positive argument for the logical possibility of Vincent's journey; however this story only describes one particular example of time travel. For this reason, the discussion above only serves to provide an argument for the logical possibility of one specific time travel journey (or a journey very similar to it). Nevertheless, this argument remains philosophically interesting, as it allows us to rebut claims that time travel is essentially inconsistent.

Many philosophers do not argue that time travel is essentially inconsistent. Instead, they merely allege that certain kinds of time travel are inconsistent. They might, for example, accept the consistency of forwards time travel journeys whilst denying the possibility of backwards time travel journeys. Arguments such as the Changing-the-Past Objection and the Grandfather Paradox do exactly this. There are many facts in Vincent's time travel story that could have been different, and it is unclear whether or not his story would have remained ideally conceivable if these facts had been altered. In the following two chapters I will make modifications to Vincent's story in order to show that the conceivability thesis can be used to make a positive argument for the logical possibility of other kinds of time travel. In Chapters 4 and 5 I will discuss how the conceivability of each of these different kinds of time travel has different implications for which metaphysical views we choose to adopt.

\section{Distinguishing Between Different Kinds of Time Travel Journeys}

All time travel journeys fall into one of four categories. We can identify these categories by distinguishing between time travel journeys in two different ways. 


\subsection{Distinguishing Time Travel Journeys by Direction}

The most obvious way in which we can distinguish a time travel journey is by its direction. A time travel journey can be either a journey forward in time or a journey backward in time. A forwards time travel journey will take the time traveller to some point in time later than their point of departure, while a backwards time travel journey will take them to some point in time earlier than their point of departure. Earlier we identified $p$ as the period of time travelled by the time traveller during a time travel journey. A time travel journey will be a forwards time travel journey where $p>0$. In contrast, a time travel journey will be a backwards time travel journey where $p<0$.

In Vincent's story, $p$ is 6 hours. Vincent's journey is therefore a forwards time travel journey.

\subsection{Distinguishing Time Travel Journeys by Duration}

Time travel journeys can also be distinguished by their duration. A time travel journey can either be instantaneous (taking no time at all) or gradual (taking some amount of time). Earlier we identified $d$ as the duration of the time traveller's journey from the perspective of the time traveller. A time travel journey will be instantaneous where $d=0$. This is the sort of time travel seen in the films Back to the Future and Los Cronocrimenes (Timecrimes). ${ }^{54}$ A time travel journey will be gradual where $d>0$. This is the sort of time travel seen in H.G. Wells' The Time Machine ${ }^{55}$ and the film Primer. ${ }^{56}$

In Vincent's story, $d$ is 0 . Vincent's journey is therefore an instantaneous time travel journey.

\footnotetext{
${ }^{54}$ Los Cronocrímenes (Timecrimes), Dir. Nacho Vigalondo, Karbo Vantas Entertainment, 2007.

${ }_{55}^{5}$ H.G. Wells, The Time Machine (London: Penguin Group, 2005).

${ }^{56}$ Primer, Dir. Shane Carruth, THINKFilm, 2004.
} 


\subsection{Different Kinds of Time Travel}

By combining these two distinctions we can identify four different categories of time travel:

1. Instantaneous forwards time travel;

2. Gradual forwards time travel;

3. Instantaneous backwards time travel; and

4. Gradual backwards time travel.

Vincent's journey (a case of instantaneous forwards time travel) represents only one of these four categories.

In the next two chapters I will consider the conceivability of each of these categories of time travel. In order to do this, I will assume that Vincent's initial story (hereafter referred to as VS1) is ideally conceivable. I will then begin to make alterations to Vincent's story and reassess whether or not its conceivability remains. I will show that there are several categories of time travel which are ideally conceivable. In doing so, I will use the conceivability thesis to provide a positive argument for the logical possibility of a number of different kinds of time travel.

\section{Conceiving of Instantaneous Forwards Time Travel Journeys}

The first category of time travel I will consider is instantaneous forwards time travel. This kind of time travel occurs whenever a time traveller finds him or herself instantaneously transported to some point in time later than his or her time of departure.

Vincent's journey is a typical case of instantaneous forwards time travel. Vincent's journey is also ideally conceivable. If we can conceive ideally of an instantaneous time travel journey six hours into the future, then we are just as capable of ideally conceiving of an instantaneous time travel journey of any other length. In order to demonstrate this, 
suppose we altered the facts of Vincent's story so that it read as follows (facts altered from VS1 appear in bold):

VS2: Vincent has built a time machine. Vincent steps into the machine at $12.00 \mathrm{pm}$ on Wednesday $1^{\text {st }}$ January 2020 . He sets the destination time on the machine's control panel to “6.00pm Monday $1^{\text {st }}$ January 2120" and presses the 'On' button. The machine disappears. At $6.00 \mathrm{pm}$ on Monday $1^{\text {st }}$ January 2120 the machine reappears. The physical processes going on within Vincent and the time machine are now exactly as they would have been immediately after Vincent pressed the 'On' button at $12.00 \mathrm{pm}$ if he had not in fact pressed the button. Vincent exits the time machine (conveniently located in his garage) and goes into his living room. Once there, he makes a cup of tea and turns on the television to watch the six o'clock news.

In order to conceive ideally of VS2, we must once again be capable of coherently imagining a possible world in which the story takes place. As with VS1, this boils down to our ability to imagine a world in which four specific facts are true, each of which is required in order for the story to be describing a genuine case of instantaneous forwards time travel:

1. Vincent and his time machine disappear at $12.00 \mathrm{pm}$ on Wednesday $1^{\text {st }}$ January 2020

2. Vincent and his time machine appear at $6.00 \mathrm{pm}$ on Monday $1^{\text {st }}$ January 2120.

3. Upon appearing, Vincent is able exit his time machine and physically interact with the world around him.

4. Upon appearing, Vincent's immediately prior experience is of having pressed the 'On' button in his time machine at $12.00 \mathrm{pm}$ on Wednesday $1^{\text {st }}$ January 2020.

The only difference between these facts and the facts of VS1 is the time and date of Vincent's appearance. When discussing VS1, we found that we had no problem with imagining a possible world in which persons disappeared and appeared. We demonstrated our ability to imagine such a world coherently by showing that (1) Vincent's story was capable of forming the basis of a narrative in which we could become fully immersed, and (2) we could fill in extra facts in the story without any contradiction revealing itself. 
The same remains true of VS2. The specific time of Vincent's appearance has no bearing on our ability to conceive ideally of his journey. If we can imagine coherently a world in which Vincent disappears and appears at some temporal distance (as we did in VS1), then we can continue to do this whatever that temporal distance might be.

As evidence of this, VS2 is just as capable as VS1 of forming the basis of a narrative in which we could become fully immersed. We can illustrate this via an analogy with journeys through space. This is not to say that time and space are analogous (though this is the view the four-dimensionalist would take), but rather that journeys - be they through space, time, or any other dimension - are analogous. All journeys have beginnings, ends, lengths, and durations. There are also many things which we can say about journeys through space which we can also say about journeys through other dimensions. It will always be impossible, for example, for one journey to be longer than another when both journeys are of the exact same length.

Suppose that we established that we were capable of fully immersing ourselves in a particular story about spatial travel. In this story, the traveller (whom we shall call Harold) drives from Wellington to New Plymouth. Suppose, then, that we wished to alter the length of his journey, so that it now ends in Auckland. Does doing this affect our ability to fully immerse ourselves in his story? Clearly, it does not. No new element has been added to the story which thwarts our immersion, nor are we suddenly required to willfully ignore some particular inconsistency in the narrative. The same is true of instantaneous time travel. If VS1 can form the basis of a story in which we can become fully immersed, then so too can an instantaneous time travel journey of any other length.

We are also still able to fill in extra facts in VS2 without any contradiction revealing itself. There may be some difficulties; how, for example, do we know that Vincent's home will still be standing in one hundred years time? How do we know that the 6 o'clock news will still exist? This is not a problem for our ability to imagine coherently a case of instantaneous forwards time travel however, as all we must do is imagine a world in which this is the case. Further, what Vincent does upon exiting his time-machine is incidental. You will recall that the only reason these facts were included in the first place was to clarify that Vincent was capable of physically interacting with the world around him 
upon his arrival in the future (a necessary requirement of genuine time travel). All that is needed is that Vincent does something upon exiting his time machine - it doesn't really matter what it is. So long as we can imagine coherently a possible world in which this happens, then the instantaneous time travel journey simpliciter remains ideally conceivable.

It does not matter whether a time traveller travels six hours into the future, or six centuries into the future. If we can conceive ideally of Vincent's first time travel journey, then we can conceive ideally of any instantaneous forwards time travel journey. Assuming the truth of the conceivability thesis, this also shows that all instantaneous forwards time travel journeys are logically possible.

\section{Conceiving of Gradual Forwards Time Travel Journeys}

The second category of time travel I will consider is gradual forwards time travel. This kind of time travel occurs whenever a time traveller finds him or herself transported to some point in time later than his or her time of departure, but takes some amount of time get there. Think of the Doctor walking around in his TARDIS while he journeys towards the future, or the time traveller in The Time Machine watching the world change around him as the days click by. We can alter Vincent's story so that it too describes a case of gradual forwards time travel (facts altered from VS1 appear in bold):

\footnotetext{
VS3: Vincent has built a time machine. Vincent steps into the machine at $12.00 \mathrm{pm}$ on Wednesday $1^{\text {st }}$ January 2020 . He sets the destination time on the machine's control panel to “6.00pm Wednesday $1^{\text {st }}$ January 2020" and presses the 'On' button. The machine disappears. At 6.00pm that same day the machine reappears. The physical processes going on within Vincent and the time machine are now exactly as they would have been thirty minutes after Vincent pressed the 'On' button at $12.00 \mathrm{pm}$ if he had not in fact pressed the button. Vincent and his time machine have undergone thirty minutes of normal causal processes since the button was pressed. Vincent exits the time machine (conveniently located in his garage) and goes into his living room. Once there, he makes a cup of tea and turns on the television to watch the six o'clock news.
} 
Does changing Vincent's story from a case of instantaneous forwards time travel to a case of gradual forwards time travel affect its conceivability? In order for us to conceive ideally of this story, we must once again be capable of coherently imagining a possible world in which four facts are true.

1. Vincent and his time machine disappear at $12.00 \mathrm{pm}$ on Wednesday $1^{\text {st }}$ January 2020.

2. Vincent and his time machine appear at $6.00 \mathrm{pm}$ on Wednesday $1^{\text {st }}$ January 2020.

3. Upon appearing, Vincent is able to exit his time machine and physically interact with the world around him.

4. Upon appearing, Vincent and his time machine have undergone thirty minutes of normal causal processes since the 'On' button was pressed at $12.00 \mathrm{pm}$ on Wednesday $1^{\text {st }}$ January 2020.

The only difference between these facts and the facts of VS1 is what has happened to Vincent and his time machine prior to appearing. Can we still imagine coherently a possible world in which this story takes place?

There is no reason why the duration of Vincent's journey should affect the ability of the story to form the basis of a narrative in which we could fully immerse ourselves. Recall the analogy of Harold's spatial journey. If changing the point of Vincent's appearance is like changing the final destination of Harold's journey, then changing the duration of Vincent's journey is like changing the duration of Harold's journey. How long Harold takes to get from Wellington to Auckland has no bearing on our ability to immerse ourselves in that story. Likewise, how long Vincent takes to get from $12.00 \mathrm{pm}$ to $6.00 \mathrm{pm}$ has no bearing on our ability to immerse ourselves in this story. Changing the temporal length of a spatial journey may affect the plausibility of a story (say, if Harold managed to complete the entire journey in mere seconds), but this does not preclude us from immersing ourselves in the narrative. There are many implausible science fiction stories that we are nevertheless capable of fully immersing ourselves in. 
The difficulty for gradual forwards time travel arises when we try to fill in extra facts in the story. Suppose that we wanted to describe Vincent's experiences during his journey. Where and when do these experiences take place?

\subsection{Journeying Forwards Outside of Time and Space}

One solution might be to simply say that Vincent and his time machine are nowhere and nowhen during their journey. They are journeying outside of time and space. There is nothing conceptually problematic about an entity ceasing to have a spatio-temporal location. The same phenomenon occurs in cases of instantaneous time travel (recall VS1, where Vincent and his time machine are also without a spatial or temporal location between the times of $12.00 \mathrm{pm}$ and $6.00 \mathrm{pm})$. Indeed, people and objects lack spatiotemporal locations all the time - both before they are created and after they are destroyed. What is conceptually problematic for cases of gradual time travel is that something happens to the object during the period that it is without a location. This is what I shall refer to as the No-Location Problem.

In VS1 we did not need to fill in any facts regarding where and when Vincent was located during his journey. This was because the journey was instantaneous. Vincent simply did not exist during the journey, and therefore did not need to go anywhere. Put in terms of person-stages, one of Vincent's person-stages existed at $12.00 \mathrm{pm}$ as he pressed the 'On' button. His very next person-stage existed at 6.00pm just as he removed his finger from the 'On' button. Vincent had no person stages located between $12.00 \mathrm{pm}$ and $6.00 \mathrm{pm}$, so these person stages did not need to be spatially or temporally located.

The same solution cannot be given with a case of gradual time travel. In the above story Vincent departs from $12.00 \mathrm{pm}$ and takes thirty minutes to reach his destination of $6.00 \mathrm{pm}$ that same day. During this thirty minute period the time traveller and his time machine continue to undergo a number of ordinary causal processes. Vincent's neurons fire, his body ages and his stomach continues to digest his last meal. Likewise, around him his machine undergoes certain changes. The clock on the control panel ticks away normally, and the machine continues to degrade in the same way as any other machine 
might - the pipes rust, the rubber valves become brittle (albeit imperceptibly during such a short space of time).

If we are to imagine coherently a possible world in which such a story takes place, we must be able to fill in facts regarding where and when these events occur. But how can we do this? The time traveller is no longer located at $12.00 \mathrm{pm}$, nor has he yet arrived at $6.00 \mathrm{pm}$. His disappearance upon pressing the 'On' button also makes it clear that he is not located at any particular spatio-temporal point between $12.00 \mathrm{pm}$ and $6.00 \mathrm{pm}$.

Consider an analogous case. Imagine that an orchestra is playing a performance of Tchaikovsky's 1812 Overture. Part-way through this performance the orchestra pauses, waits 5 minutes, then resumes playing. Such an occurrence is analogous to a case of instantaneous time travel. Just as the time traveller and his time machine can be without a spatio-temporal location for some period of time, so too can a particular performance of Tchaikovsky. Consider, however, what we would make of a case where the orchestra resumes playing having already played an additional minute of the song. That is not to say that they have skipped a minute of the song, nor have they sneakily played that minute during a period of inattentiveness by the audience. The additional minute has been played, but not at any specific place or time.

This is essentially what is occurring in VS3. Something happens, but it does not happen in any specific place or time. Such an occurrence is nonsensical, and provides an incredibly large stumbling block for our ability to imagine coherently a possible world in which such a story takes place.

We can include additional facts in VS3 to further highlight this problem. Consider the following (facts altered from VS3 appear in bold):

\footnotetext{
VS3*: Vincent has built a time machine. Vincent steps into the machine at $12.00 \mathrm{pm}$ on Wednesday $1^{\text {st }}$ January 2020 and sets the alarm on his wristwatch to go off in 15 minutes time. He sets the destination time on the machine's control panel to " $6.00 \mathrm{pm}$ Wednesday $1^{\text {st }}$ January 2020" and presses the 'On' button. The machine disappears. At $6.00 \mathrm{pm}$ that same day the machine reappears. The physical processes going on within Vincent and the time machine are now exactly as they would have been thirty minutes after
} 
Vincent pressed the 'On' button at $12.00 \mathrm{pm}$ if he had not in fact pressed the button. Vincent and his time machine have undergone thirty minutes of normal causal processes since the button was pressed. Vincent's wristwatch alarm sounded 15 minutes into the journey. Vincent exits the time machine (conveniently located in his garage) and goes into his living room. Once there, he makes a cup of tea and turns on the television to watch the six o'clock news.

Where and when did Vincent's wristwatch alarm go off? We cannot fill in this particular fact, and therefore cannot imagine coherently a possible world in which VS3 occurs.

\subsection{Journeying Forwards Through Time and Space}

We can, however, modify VS3 in an attempt to make it ideally conceivable. In order to solve the No-Location Problem, we must make it so everything that happens to Vincent and his time machine does so at some spatio-temporal location. This is best done by making Vincent journey through time and space, as opposed to outside of it. We can do this by altering his story so that the time-machine no longer disappears, but instead stays physically present throughout the journey (facts altered from VS3* appear in bold):

\footnotetext{
VS4: Vincent has built a time machine. Vincent steps into the machine at $12.00 \mathrm{pm}$ on Wednesday $1^{\text {st }}$ January 2020 and sets the alarm on his wristwatch to go off in 15 minutes time. He sets the destination time on the machine's control panel to " $6.00 \mathrm{pm}$ Wednesday $1^{\text {st }}$ January 2020" and presses the 'On' button. The machine stays where it is. At 6.00pm that same day the physical processes going on within Vincent and the time machine are now exactly as they would have been thirty minutes after Vincent pressed the 'On' button at $12.00 \mathrm{pm}$ if he had not in fact pressed the button. Vincent and his time machine have undergone thirty minutes of normal causal processes since the button was pressed. Vincent's wristwatch alarm sounded 15 minutes into the journey. Vincent exits the time machine (conveniently located in his garage) and goes into his living room. Once there, he makes a cup of tea and turns on the television to watch the six o'clock news.
}

This alteration makes it clear that the physical processes going on within the time machine during its journey (including the sounding of the wristwatch alarm) all occur in the space where the time machine is located. 
But this still leaves the question of when events within the time machine occur.

One solution might be as follows: If the alarm goes off halfway through the thirtyminute duration of the journey, then it stands to reason that this will happen halfway through the six-hour period of time that is being travelled. That is, at $3.00 \mathrm{pm}$. This is a risky move however, as it invites the question of whether or not we are still conceiving of a case of genuine time travel. If Vincent is temporally located at $3.00 \mathrm{pm}$ fifteen minutes into his journey, then this seems to mean that he will be temporally located at $4.00 \mathrm{pm}$ twenty minutes into his journey, $5.00 \mathrm{pm}$ twenty-five minutes into his journey and finally $6.00 \mathrm{pm}$ thirty minutes into his journey. Why is this problematic? Consider a similar story (facts altered from VS4 appear in bold):

\footnotetext{
VS5: Vincent has built a suspended animation machine. Vincent steps into the machine at $12.00 \mathrm{pm}$ on Wednesday $1^{\text {st }}$ January 2020 and sets the alarm on his wristwatch to go off in 15 minutes time. He sets the 'Suspension' on the machine's control panel to " $1 / 12$ normal rate for a period of six hours" and presses the 'On' button. The machine stays where it is. At $6.00 \mathrm{pm}$ that same day the physical processes going on within Vincent and the suspended animation machine are now exactly as they would have been thirty minutes after Vincent pressed the 'On' button at $12.00 \mathrm{pm}$ if he had not in fact pressed the button. Vincent and his suspended animation machine have undergone thirty minutes of normal causal processes since the button was pressed. Vincent's wristwatch alarm sounded 15 minutes into the journey. Vincent exits the suspended animation machine (conveniently located in his garage) and goes into his living room. Once there, he makes a cup of tea and turns on the television to watch the six o'clock news.
}

In VS5 we have a story of a suspended animation machine - that is, a machine which can slow or halt physical processes. VS5 is not a time travel story, as there is no discrepancy between the duration of the journey and the distance being travelled. Vincent is physically present at every moment between $12.00 \mathrm{pm}$ and $6.00 \mathrm{pm}$. During this time Vincent progresses forward through time just as every other individual does. The only difference is that Vincent experiences less as this progression occurs (for every hour of time the rest of the world experiences, Vincent experiences only five minutes). His story is no different from the story of an individual who slips into some sort of hibernation. 
The problem for the conceivability of gradual time travel is that the important features of VS5 are identical to those of VS4. Indeed, the only difference between the two stories is the name given to Vincent's machine. How then, can we be sure that what we are conceiving of in VS4 is in fact a case of time travel and not of something else such as suspended animation? It seems that once we alter the story to provide a solution to the NoLocation Problem (as we did from VS3 to VS4) we are left with a story which no longer describes a case of genuine time travel. Put simply, we may very well be capable of ideally conceiving of Vincent's story in VS4, but what we are conceiving of is not a time travel story.

\subsection{Re-evaluating 'Genuine’ Time Travel}

It is clear that whatever is happening in VS4, it is the very same kind of thing as that which happens in VS5. Our intuitive response is to hold that neither VS4 nor VS5 describes a case of genuine time travel, but there is an alternative. We could instead argue that both stories are in fact time travel stories. That is, we could argue that Vincent's journey in the suspended animation machine in VS5 does amount to time travel.

In the TV series Futurama, Phillip J. Fry accidentally enters a suspended animation machine and finds himself frozen for one thousand years. ${ }^{57}$ For Fry, this time passes in an instant. Surely such a journey should be considered time travel? Fry has journeyed into the actual future, he is capable of physically interacting with the world around him, and there seems to be a clear discrepancy between how much time he has experienced (zero seconds) and the period of time he has traversed (one thousand years). To any bystander, it seems that Fry has experienced exactly what Marty McFly would have experienced had he set the controls of his time machine for a one thousand year journey into the future.

Alas, Fry's journey is still very different to Marty's. It is true that there seems to be a time discrepancy in the case of Fry's journey into the future. Likewise, in VS5 there appears to be a discrepancy between the duration of Vincent's journey (thirty minutes) and

\footnotetext{
57 'Space Pilot 3000', Futurama, Dirs. Rich Moore and Gregg Vanzo, The Curiosity Company and Twentieth Century Fox, 1999.
} 
the period of time he has traversed (six hours). These are not, however, the sorts of time discrepancies that are necessary for a case of genuine time travel. Experiencing time faster is not the same as experiencing a time discrepancy. In order to illustrate this, it is useful to once again draw an analogy with spatial journeys.

Imagine that before setting off on his journey to Auckland, Harold claims he will carry out the journey by 'space travelling'. He explains that space travelling is, by definition, travelling in such a way that there is a discrepancy between the spatial length of a traveller's journey and the spatial distance that he traverses. Someone who space travels is therefore able to travel to other locations very quickly by 'skipping over' some of the distance between their points of departure and arrival. Harold gets into his car and commences his journey from Wellington to Auckland - a distance of approximately 493 kilometres. At the same time, a number of other travellers set out on the same journey, though these travellers intend to use far more traditional means of transportation. A few hours later, Harold arrives in Auckland. Harold has duly beaten all of the other travellers to their destination. Indeed, Harold has completed the journey in record time. Despite this however, the odometer on Harold's car reads as having travelled 493 kilometres since leaving Wellington. As the other travellers arrive, he notes that their odometers display this same distance.

Is Harold a genuine space traveller? Or has he merely travelled from Wellington to Auckland at an incredibly fast speed?

Clearly, Harold is not a space traveller. There is no discrepancy between the spatial length of his journey (493 kilometres) and the spatial distance he has travelled (493 kilometres). Harold may have succeeded in travelling from Wellington to Auckland faster than anyone else, but he has nevertheless passed through every kilometer along the way. Fry - and Vincent from VS5 - are exactly the same. Although they may get to some future point "faster" than anyone else, they nevertheless pass through every point in time along the way. The way in which Fry and Vincent move forward through time is exactly the same way in which I move through time now as I sit at my desk typing. The only 
difference is the rate at which they do this. D.H. Mellor agrees with this position, arguing that: 58

What is called forward time travel is neither a problematic nor an especially remarkable phenomenon. To call it that is simply to give a misleadingly portentous description of situations in which our mental and bodily processes take longer than they normally do.

Gradual forwards time travel through time and space is not time travel at all - it is simply a sped-up version of what each of us does on an everyday basis.

This revelation holds ramifications for a number of popular time travel stories. In The Time Machine, the time traveller travels to the future in exactly the same way as Vincent in VS4. If our conclusion is correct, then the time traveller in this story is not in fact time travelling, but merely slowing down the physical processes of himself, his machine, and everything else within its field of effect. ${ }^{59}$ This argument also poses problems for the possibility of time travel under Albert Einstein's Special Theory of Relativity. The theory dictates that objects travelling at different speeds will experience time at different rates. ${ }^{60}$ Put simply, the faster you go, the slower time passes. Empirical observation has confirmed this effect, and been used as evidence for the actual occurrence of (albeit very small) cases of forwards time travel. ${ }^{61}$ If our conclusion is correct, however, then these observations do not provide evidence for the possibility of time travel. However fast an object or person might travel, this will never cause them to experience a time discrepancy. They may experience time more quickly than anyone else, but they will nevertheless journey through every point in time along the way. They are not time travellers.

\footnotetext{
${ }^{58}$ D.H. Mellor, Real Time II (London: Routledge, 1988), p. 124.

${ }^{59}$ The title of this book is not a complete misnomer however; as the machine is also capable of taking the traveller backwards in time - a clear case of time travel.

${ }^{60}$ Paul Davies, 'How to Build a Time Machine', Scientific American, Vol. 21, No. 1 (Spring 2012), p. 26.

${ }^{61}$ Ibid.
} 


\section{Conclusion}

Instantaneous forwards time travel is ideally conceivable. If we can imagine coherently a possible world in which Vincent's first story (VS1) occurs, then we can imagine coherently a possible world in which any case of instantaneous forwards time travel occurs, regardless of the period of time being traversed. Assuming the truth of the conceivability thesis, this means that instantaneous forwards time travel journeys are logically possible.

Ideally conceiving of gradual forwards time travel is more difficult. The NoLocation problem means that we cannot conceive of such journeys if the time traveller and his machine do not remain physically present throughout their journey. If, however, they are physically present throughout their journey, then the story becomes conceivable, but fails to be a story of time travel. We cannot, therefore, conceive ideally of a case of gradual forwards time travel. While this does not necessarily demonstrate the impossibility of such journeys, it does prevent us from putting forward a positive argument for their logical possibility based upon the conceivability thesis. 


\section{Chapter 3: Conceiving of Other Time Travel Journeys - Backwards Time Travel}

\section{Introduction}

In the previous two chapters I have put forward a positive argument for the logical possibility of forwards time travel. I have argued that all instantaneous forwards time travel journeys are ideally conceivable and (assuming the truth of the conceivability thesis) logically possible. I will now turn to consider the conceivability of backwards time travel journeys.

\section{Sidestepping the Usual Objections to the Possibility of Backwards Time Travel}

The logical possibility of backwards time travel is ordinarily considered more contentious than that of forwards time travel. As noted above, it is argued that certain scientific theories and empirical observations provide evidence for the physical - and thus also logical - possibility of journeys into the future. ${ }^{62}$

I have argued that journeys of this kind do not count as genuine cases of time travel, most notably because they fail to meet the time discrepancy requirement. Despite this, however, these sorts of journeys are something very much like genuine forwards time travel. Their physical possibility at the very least serves to make the logical possibility of genuine forwards time travel journeys (that is, forwards time travel journeys which are instantaneous) far more palatable. If any contradiction were to arise out of a genuine case of forwards time travel, then it seems that this same contradiction should arise out of the sort of journeys into the future that the Special Theory of Relativity already allows us to make. The fact that no such contradictions arise is good news for the logical possibility of genuine forwards time travel.

\footnotetext{
${ }^{62}$ See above at page 40.
} 
A second reason that the possibility of backwards time travel is usually seen as more contentious than the possibility of forwards time travel is that there a number of very powerful arguments which apply to the former, but not the latter. One of the most notorious of these objections (and one which I discussed above with reference to Marty's journey in Back to the Future $)^{63}$ focuses on the impossibility of changing the past. This argument can be stated as follows:

1. If backwards time travel is possible, then it is possible to change the past.

2. Changing the past is logically impossible.

Therefore,

3. Backwards time travel is logically impossible.

The second premise of this argument is clearly true. The past cannot be changed. To suggest that we can change the past is to hold that something both can and cannot be the case at the same point in time (like Marty's parents both meeting and not meeting in 1955). Statements such as this are clearly contradictory.

Where the argument goes wrong is in its confusion of the logical possibility of a backwards time travel journey with the logical possibility of certain actions that the time traveller tries to carry out upon arriving in the past. Put simply, the changing-the-past objection argues that if a time traveller travels to the past and tries to do something impossible, then backwards time travel must be impossible. But this simply does not follow. Consider an analogous case. Suppose that I tried to demonstrate the logical impossibility of travelling from Wellington to Auckland by retelling Harold's story in the following way:

Harold travels by car from Wellington to Auckland. Upon arriving in Auckland he sits down with a pen and paper and draws a three-sided square.

It does not make sense to say that Harold's attempt to do something logically impossible upon arriving at his destination necessarily renders the preceding journey logically impossible. Harold's journey is still possible, even though what he attempts to do

\footnotetext{
${ }^{63}$ See above at page 12.
} 
upon arriving at his destination is not. Something will stop Harold from drawing that shape, but it need not be the failure of his journey. So too is it with backwards time travel. Something will prevent the time traveller from changing the past, ${ }^{64}$ but there is no reason why that thing will be the necessary failure of his backwards time travel journey.

In order for the changing-the-past objection to avoid the above confusion, it must be changed to the following:

1. If a backwards time travel journey is possible, then it is possible to change the past.

2. Changing the past is logically impossible.

Therefore,

3. Backwards time travel is logically impossible.

In doing this, however, it becomes clear that the first premise is false. The possibility of a backwards time travel journey no more entails the possibility of changing the past than the possibility of a journey from Wellington to Auckland entails the possibility of drawing a three-sided square. The possibility of a backwards time travel journey merely entails the possibility of departing from the present, and arriving at some time in the past.

In this chapter I will focus only on the ideal conceivability of backwards time travel journeys. There may be many impossible things that a time traveller is incapable of doing upon arriving in the past, but all that I wish to prove is that getting there is logically possible.

\section{Conceiving of Instantaneous Backwards Time Travel Journeys}

The first kind of time travel I will consider is instantaneous backwards time travel. This kind of time travel occurs whenever a time traveller finds him or herself

\footnotetext{
${ }^{64}$ Here we might appeal to all sorts of explanations - Timelords, mystical powers, or Lewis' simple notion that a time traveller will not do something because they did not do that thing.
} 
instantaneously transported to some point in time earlier than his or her time of departure. Once again, we can amend the facts of Vincent's story so that it describes such a journey (facts altered from VS1 are in bold):

VS6: Vincent has built a time machine. Vincent steps into the machine at $12.00 \mathrm{pm}$ on Wednesday January $1^{\text {st }} 2020$. He sets the destination time on the machine's control panel to “6.00am Wednesday January $1^{\text {st }} \mathbf{2 0 2 0 "}$ and presses the 'On' button. The machine disappears. At 6.00am Wednesday January $1^{\text {st }} 2020$ the machine appears. The physical processes going on within Vincent and the time machine are now exactly as they would be immediately after Vincent presses the 'On' button at $12.00 \mathrm{pm}$ if he does not in fact press the button. Vincent exits the time machine (conveniently located in his garage) and goes into his living room. Once there, he makes a cup of tea and turns on the television.

In order to conceive ideally of this story, we must once again be capable of coherently imagining a possible world in which four facts hold.

1. Vincent and his time machine disappear at $12.00 \mathrm{pm}$ on Wednesday January $1^{\text {st }}$ 2020.

2. Vincent and his time machine appear at 6.00am Wednesday January $1^{\text {st }} 2020$

3. Upon appearing, Vincent is able to exit his machine and physically interact with the world around him.

4. Upon appearing, Vincent's immediately prior experience is of having pressed the 'On' button in his time machine, and this event occurred at $12.00 \mathrm{pm}$ on Wednesday January $1^{\text {st }} 2020$.

These are, incidentally, very similar to the four facts that we had to imagine when conceiving of Vincent's first story. The only difference now is the temporal order in which these events occur. Does this make any difference to our ability to conceive ideally of the story?

We clearly have no problem imagining a world in which each of these four facts is separately true. As demonstrated in previous chapters, there is no difficulty in imagining a man with certain experiences, or a man who is capable of physically interacting with the world around him. We can also easily imagine disappearances and appearances, and we 
can imagine these happening at some temporal distance. What, then, is to stop us from imagining these events occurring in an unusual order? To be clear, in VS1 our ability to imagine Vincent's disappearance was not reliant on his appearance at some later time. We could just as easily have conceived of Vincent merely disappearing without a following appearance. Likewise, our ability to imagine Vincent's appearance did not seem to rely on a prior disappearance. Consider, for example, a truncated account of Vincent's first story:

\begin{abstract}
At $6.00 \mathrm{pm}$ on Wednesday $1^{\text {st }}$ January 2020 Vincent and his time machine appear. Upon appearing, Vincent's immediately prior experience is of having pressed the 'On' button in his time machine at $12.00 \mathrm{pm}$ on Wednesday January $1^{\text {st }} 2020$ Vincent exits the time machine (conveniently located in his garage) and goes into his living room. Once there, he makes a cup of tea and turns on the television to watch the six o'clock news.
\end{abstract}

We do not need any more information in order to be capable of imagining a possible world in which this story takes place, nor do we need to check that this appearance was preceded by a disappearance. The story might be unusual without some prior disappearance, but it is certainly not unimaginable. Consider what happens if we make the following alteration:

\footnotetext{
At 6.00am on Wednesday $1^{\text {st }}$ January 2020 Vincent and his time machine appear. Upon appearing, Vincent's immediately prior experience is of having pressed the 'On' button in his time machine at $12.00 \mathrm{pm}$ on Wednesday January $1^{\text {st }} 2020$. Vincent exits the time machine (conveniently located in his garage) and goes into his living room. Once there, he makes a cup of tea and turns on the television.
}

Do we need to check that this appearance is followed by a disappearance? We do not. Once again, a later disappearance will make more sense of this appearance, but it is certainly not necessary in order for us to be able to imagine a possible world in which this series of events occurs. Neither disappearances nor appearances rely on a specific temporal ordering in order to be imaginable. For this reason, we should have no difficulty in imaging a world in which an appearance is followed by a disappearance.

We can therefore imagine a possible world in which VS7 takes place. Can we imagine such a world coherently however? 
If we assume that VS1 is capable of forming the basis of a story in which we could fully immerse ourselves, then it seems difficult to see how merely changing the order of Vincent's disappearance and appearance could suddenly prevent us from becoming immersed. We can still fill in extra facts without a contradiction revealing itself. We can, in fact, fill in the very same facts we were able to fill in for VS1. Vincent's journey is still instantaneous, so we are not required to explain where (or when) he goes during his journey. We might create a contradiction by filling in facts regarding what Vincent does after his journey (he might, for example, stop himself from travelling back in time in the first place), but as discussed above, this does not affect the conceivability of his journey, but rather the conceivability of what Vincent tries to do upon arriving in the past.

Indeed, as with instantaneous forwards time travel, it seems that we can even change the period of time travelled without affecting our ability to imagine coherently a world in which the story takes place. It matters very little whether Vincent journeys back in time six hours, six days, or six centuries.

It is true that we could select a destination (both spatial and temporal) where Vincent did not appear. We could, for example, send Vincent back in time five minutes despite knowing that no time machine appeared at this time. Such a story is an unfair move however, and bears striking similarities to those stories in which time travellers arrive in the past only to attempt some impossible feat. Arriving at a temporal location where you never arrived is logically impossible, but this is a trivial inconsistency. Any journey can be rendered unimaginable by including a contradiction such as this. Consider again Harold's story, and suppose that we told it as follows:

Harold travels by car from Wellington to Auckland. He arrives at a destination at which he does not arrive.

Such a story is clearly inconceivable, but that is exactly what we would expect. The inconceivability of this contradictory story does not provide us with any interesting insight into the possibility of journeys from Wellington to Auckland. The same is true of backwards time travel. It is, of course, impossible for someone to arrive at a temporal location where they never arrived, but this is no more a limitation on the possibility of 
backwards time travel than the impossibility of someone arriving at a spatial location where they never arrived is a limitation on spatial travel. To tell a story in which a time traveller goes somewhere they do not - and then hold this out as proof of the impossibility of backwards time travel - is to unfairly import a contradiction into the story from the getgo. It is, for this very reason, a bad argument.

Any backwards time travel story which describes a time traveller travelling to somewhere he never went will always be inconceivable, ${ }^{65}$ but this tells us nothing about the possibility of instantaneous backwards time travel journeys. All stories like Vincent's (regardless of the period of time being travelled) avoid this problem. This is because fact (2) clearly states that the time traveller and his time machine did arrive at the point in time to which they are travelling. For this reason, any instantaneous backwards time travel which appears in the same coherent fashion as Vincent's will be ideally conceivable and, therefore, logically possible.

\section{Conceiving of Gradual Backwards Time Travel Journeys}

We can conceive ideally of most instantaneous backwards time travel journeys, but can the same be said of gradual backwards time travel journeys? This kind of time travel will occur whenever a time traveller finds him or herself transported to some point in time earlier than his or her time of departure, but takes some amount of time get there. Vincent's story can be altered once again to make it a story of gradual backwards time travel (facts altered from VS6 appear in bold):

VS7: Vincent has built a time machine. Vincent steps into his time machine at $12.00 \mathrm{pm}$ on Friday January $1^{\text {st }} 2010$. He sets the 'Destination' time on the machine's control panel to “6.00am Wednesday $1^{\text {st }}$ January 2020" and presses the 'On' button. The machine disappears. At 6.00am on Wednesday $1^{\text {st }}$ January 2020 Vincent and the time machine appear. The physical processes going on within Vincent and the time machine are exactly as they would be thirty minutes after Vincent presses the 'On' button at $12.00 \mathrm{pm}$ if he does not in fact pressed the button. Vincent and his time machine have undergone thirty minutes of normal causal processes since the button was pressed.

\footnotetext{
${ }^{65}$ And most likely impossible - though the inconceivability of the story does not necessarily entail this.
} 
Vincent exits the time machine (conveniently located in his garage) and goes into his living room. Once there, he makes a cup of tea and turns on the television.

Once again, in order to conceive ideally of this story, we must be capable of coherently imagining a possible world in which the following four facts are true:

1. Vincent and his time machine disappear at $12.00 \mathrm{pm}$ on Wednesday January $1 \mathrm{st}$ 2020.

2. Vincent and his time machine appear at $6.00 \mathrm{am}$ on Wednesday January 1 st 2020.

3. Upon appearing, Vincent is able to exit his time machine and physically interact with the world around him.

4. Upon appearing, Vincent and his time machine have undergone thirty minutes of normal causal processes since the 'On' button was pressed at 12.00pm on Wednesday $1^{\text {st }}$ January 2020.

The first three of these facts are identical to those that appear in Vincent's instantaneous forwards time travel story, and we have already established that we are quite capable of imagining a possible world in which all of these things occur. We have also shown that we can imagine these events occurring in an unusual order (such as an appearance preceding a disappearance). The only difference between VS7 and VS6 is the fourth fact. Now, Vincent has spent thirty minutes in his time machine since pressing the button. Does this affect our ability to imagine coherently a possible world in which Vincent carries out such a journey?

It certainly does not seem to prevent Vincent's story being capable of forming the basis of a narrative in which we could become full immersed. Vincent disappears in the present and appears in the past, just as he did in VS7. The only difference is that he now takes some time to get there. As we discussed when considering gradual forwards time travel, the duration of the journey makes no difference to our ability to immerse ourselves in the story. 
Problems only arise when we attempt to apply the second test for coherent modal imagination - that is, when we try to fill in extra facts. As with gradual forwards time travel journeys, the most important fact in need of filling in is precisely where (and when) Vincent and his machine are located during their thirty minute journey.

\subsection{Journeying Backwards Outside of Time and Space}

Our first response might be to once again state that Vincent and his time machine travel outside of time and space. As we discussed in the previous chapter however, all events must have some spatial and temporal location. If Vincent experiences thirty minutes of events during his journey, then these events must take place at some point in time and space. If Vincent and his time machine journey backwards outside of time and space, then anything that happens to them during this time happens nowhere and nowhen. This is what we referred to as the No-Location Problem. The No-Location Problem is just as applicable to cases of backwards time travel as it is to cases of forwards time travel. We can illustrate this by re-introducing the wristwatch alarm to the story (facts altered from VS7 appear in bold):

VS7*: Vincent steps into his time machine at $12.00 \mathrm{pm}$ on Friday January $1^{\text {st }} 2010$ and sets the alarm on his wristwatch to go off in 15 minutes time. He sets the 'Destination' time on the machine's control panel to "6.00am Friday $1^{\text {st }}$ January 2010 " and presses the 'On' button. The machine disappears. At 6.00am that day Vincent and the time machine appear. The physical processes going on within Vincent and the time machine are exactly as they would be thirty minutes after Vincent presses the 'On' button at $12.00 \mathrm{pm}$ if he does not in fact press the button Vincent and his time machine have undergone thirty minutes of normal causal processes since the button was pressed. Vincent's wristwatch alarm sounded 15 minutes into the journey. Vincent exits the time machine (conveniently located in his garage) and goes into his living room. Once there, he makes a cup of tea and turns on the television.

If Vincent travels outside of time and space, then when and where does his watch alarm go off? 
We simply cannot imagine coherently a world in which events occur outside of time and space (recall the orchestra example from earlier) ${ }^{66}$. For this reason, a gradual backwards time travel journey outside of time and space is not ideally conceivable. As noted previously, this will not necessarily imply the impossibility of such a journey. It will, however, thwart any attempt of ours to use the conceivability thesis to make a positive argument for the logical possibility of such a journey.

In order to have any chance of ideally conceiving of a gradual backwards time travel journey, we must assume that the time traveller and his time machine journey through time and space.

\subsection{Journeying Backwards Through Time and Space}

No explicit modifications are needed in order to change the previous story to one in which Vincent and his time machine remain physically present throughout their journey. In the case of forwards time travel, it was necessary to omit the detail that the machine disappeared in order to change the story from one in which the time traveller travelled outside of time and space to one where he travelled through time and space. Here this is not required, as the machine still disappears. Whether or not Vincent's backwards time travel journey occurs outside of time and space or through time and space, the fact remains that immediately after $12.00 \mathrm{pm}$ Vincent has already departed and is heading in the opposite temporal direction. Vincent's trajectory through time can be illustrated by the dotted line below:

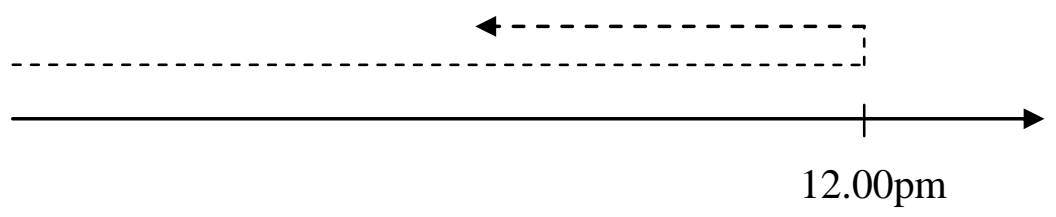

\footnotetext{
${ }^{66}$ See above at page 35.
} 
Put simply, Vincent and his machine have done a temporal 'u-turn', much in the same way that a car might turn back down a road it has just travelled.

How does this story fare for conceivability? Having Vincent travel backwards through time and space now allows us to fill in extra facts regarding where and when his experiences during the journey occur. As with gradual forwards time travel through time and space, whatever happens to Vincent during his journey happens at the very same location where his time machine was when it began moving backwards through time. As for when these events occur, assuming (as we did with forwards time travel) that he travels backwards at a constant rate, we can begin to identify when specific events occur. If his alarm goes off halfway through Vincent's journey, then it stands to reason that this will occur halfway through the distance he is attempting to travel - that is, at 9.00am.

Unlike a case of gradual forwards time travel through time and space there is no argument as to whether or not we are still conceiving of a genuine case of time travel. Since Vincent is travelling backwards in time, the period of time traversed $(p)$ is -6 hours, whilst the duration of his journey $(d)$ is 0.5 hours. So long as one of these values is negative and the other is positive there will clearly be a time discrepancy, and thus a case of genuine time travel.

\subsection{Gradual Backwards Time Travel and the Double Occupancy Problem}

By using the approach above, we can fill in facts regarding when and where Vincent is located throughout his gradual backwards time travel journey. This is a necessary requirement of our being able to imagine coherently a possible world in which VS7 occurs. In filling in these facts, however, it seems that a contradiction may very well be revealing itself. In 'Troubles with Time Travel', ${ }^{67}$ William Grey raises the following issue with cases of gradual backwards time travel through time and space: ${ }^{68}$

\footnotetext{
${ }^{67}$ William Grey, 'Troubles with Time Travel', in Philosophy, Vol. 74, No. 287 (January 1999), pp. 55-70.

${ }^{68}$ Ibid., p. 60.
} 
How can the 'movement' into the past possibly get started? We know that at times later than noon there is no machine present, since it has disappeared into the past. But what of the moments just before noon? At those times there seem to be not one but two machines - one going backwards and the other forwards - each apparently occupying (or attempting to occupy) the same location! That is, it seems that as the machine sets out into the past it will collide with itself.

This is what Grey refers to as the 'Double Occupancy Problem'.

This problem clearly applies to VS7. Suppose we label the spatial location of Vincent leading up to the time travel journey as $\mathrm{L}_{0}$. Vincent stays at $\mathrm{L}_{0}$ until he hits the 'On' button at precisely $12.00 \mathrm{pm}$, at which point Vincent continues to be located at $\mathrm{L}_{0}$, but begins to travel backwards in time. If this is a true description of events, then at 11.59.59am Vincent is located at $\mathrm{L}_{0}$ travelling forwards through time. Once Vincent presses the button, he again finds himself at $\mathrm{L}_{0}$ at $11.59 .59 \mathrm{am}$ - though this time he is travelling backwards through time. There are now two Vincents occupying the same spatio-temporal location: one who is just about to press the 'On' button and whose watch reads $11.59 .59 \mathrm{am}$, and another who has just pressed the 'On' button and whose watch reads some time after $12.00 \mathrm{pm}$.

The above diagram of Vincent's 'u-turn' is therefore not entirely accurate. Vincent's line through time does not neatly turn around in this way. Instead, it turns back on itself, attempting to cover the same ground that it has already traversed. His journey is not so much analogous to a car turning back down a road as a train on tracks attempting to reverse direction back on to itself.

Indeed, the Double Occupancy Problem will also create problems for conceivability at the other end of the journey. When Vincent arrives at 6.00am, he and his machine will begin to move forward through time in the very same location where they are also moving backwards. It is clear that we cannot imagine (let alone imagine coherently) Vincent travelling backwards through time in this way. 


\title{
4.4 Dowe's Solution to the Double Occupancy Problem
}

How then, might we modify Vincent's story in such a way as to be able to imagine coherently a case of gradual backwards time travel? Clearly, Vincent cannot inhabit the same spatio-temporal location more than once. Since gradual backwards time travel requires Vincent to travel back through his prior temporal locations, Vincent must avoid the double occupancy problem by changing his spatial location.

In 'The Case for Time Travel' ${ }^{69}$ Phil Dowe attempts to tackle the Double Occupancy Problem by using Feynman's “notorious" interpretation of particle pair creation/annihilation. According to Dowe, this interpretation argues that where: ${ }^{70}$

\footnotetext{
An electron and its antiparticle the positron collide, and disappear leaving just a certain amount of energy, we take the positron to be the same electron travelling back in time. The annihilation and creation events are interpreted to be reversals in time of the particle.
}

Dowe believes that such an interpretation provides us with a way in which we can imagine gradual backwards time travel through time and space without contradiction: ${ }^{71}$

\begin{abstract}
How does a particle turn around in time without getting in its own way? Answer: same way that two particles collide, i.e., by being in motion. How does a police box turn around in time without getting in its own way? Answer, by being in motion when it turns around. To do this sort of time travel you have to take a run up. So, for a time machine to travel back in time on the method envisaged by Grey, it could be moving across a field, and we should also see its reversed later self moving toward it... and as the switch is hit the two collide, apparently annihilating both. Thus the time machine avoids colliding with itself.
\end{abstract}

We can use Dowe's solution in our attempt to conceive of VS7. Suppose we alter the facts of this story so that Vincent and his time machine are travelling at some speed in the moments leading up to $12.00 \mathrm{pm}$. In this way, Vincent will be located at $\mathrm{L}_{-2}$ at 11.59.58am, $\mathrm{L}_{-1}$ at $11.59 .59 \mathrm{am}$, and finally $\mathrm{L}_{0}$ as he presses the button at $12.00 \mathrm{pm}$. Vincent will then begin to move backwards through time, but as he does so he also continues to

\footnotetext{
${ }^{69}$ Phil Dowe, 'The Case for Time Travel', Philosophy, Vol. 75, No. 293 (July 2000), p. 445-451.

${ }^{70}$ Ibid., p. 445.

${ }^{71}$ Ibid., p. 446.
} 
move in space - occupying $\mathrm{L}_{1}$, then $\mathrm{L}_{2}$, and so on. Thus, while Vincent is moving backwards through the temporal locations he has already occupied, he is now at a different spatial location, thus avoiding the Double Occupancy Problem.

But does this solution actually work? It allows us to fill in facts regarding where and when Vincent is located throughout his journey, but it does not entirely avoid the Double Occupancy Problem. As we fill in even more facts, we begin to see that the problem remains.

Dowe's solution would work if it was true that objects moved through space in a discrete fashion - that is, if objects were wholly located at one spatial location in one instant, and then wholly located at another spatial location in the very next instant. This is not the case however, even for very fast moving objects. From one instant to the next objects will occupy a region of space that partially overlaps with the region of space they occupied in the previous instant. Objects do not move from occupying point $\mathrm{L}_{1}$, to occupying point $\mathrm{L}_{2}$, to occupying point $\mathrm{L}_{3}$. Instead they occupy a set of points - points which overlap from one instant to the next. An object then, would move from occupying points $\mathrm{L}_{0.5}, \mathrm{~L}_{1}, \mathrm{~L}_{1.5}$, to occupying points $\mathrm{L}_{1.5}, \mathrm{~L}_{2}, \mathrm{~L}_{2.5}$, to occupying points $\mathrm{L}_{2.5}, \mathrm{~L}_{3.0}, \mathrm{~L}_{3.5}$.

Put simply, in order for Dowe's solution to work, the time machine must occupy a completely different spatial location in the instant just before, and the instant just after, the 'On' button is pressed. This is not the case however, as no matter how fast a time machine travels, it will nevertheless occupy some of the same spatial points both before and after the 'On' button is pressed. For this reason, the Double Occupancy Problem remains.

It seems then, that if we are to avoid the Double Occupancy Problem by having the time machine move, then this move must be a discreet - and instantaneous - one. The time machine must be in one spatial location immediately before the 'On' button is pressed, and a completely different spatial location immediately after it is pressed. Essentially, the time machine must teletransport. Allowing a time machine to teletransport as it begins its journey backwards in time avoids the Double Occupancy Problem, as there is no risk of the two time machines (one travelling forwards and the other travelling backwards) occupying the same space at the same time. 
Dowe considers this solution, but rejects it as it involves a 'major discontinuity'. This may be a particular problem for some metaphysical theories, but here we are solely concerned with conceivability. We have already established that we have no problem in conceiving of discontinuities of persons and objects, so it may very well be the case that incorporating a small spatial teletransportation at the very same instant that the backwards time travel journey commences is the best way to ensure the ideal conceivability of gradual backwards time travel through time and space

\subsection{An Alternative Solution to the Double Occupancy Problem}

Consider another possible solution. Imagine that the time machine works in the same way as those seen in the film Primer. That is, while the contents of the machine are transported backwards through time, the machine itself is not. The time machine then, merely demarcates a region of space in which causal processes run in reverse. Imagine further that as Vincent prepares to make his journey, the machine is already on and running.

How does this help the conceivability of gradual backwards time travel? The Temporal Collision Problem arises from the fact that two objects (or, rather, two temporal stages of the same object) are attempting to inhabit the same spatio-temporal location - one moving forwards through time, the other moving backwards. What is problematic, then, is that gradual backwards time travel allows an object to travel both forwards and backwards in time through the same spatial point. This cannot occur if our time machine operates á la Primer. For all spatial points outside of the machine, causation runs in the ordinary (forwards) direction, while for all spatial points inside the machine, causation runs in reverse. There is no spatial point where causation can run both forwards and backwards. With this sort of time machine, no time traveller (nor any object for that matter) can collide with its earlier self.

Can we more easily conceive of a gradual backwards time travel journey through time and space in this way? 
For simplicity's sake, suppose that the time machine operates in such a way that causal processes within it run in reverse at a ratio of $1: 1$. If you were to enter the time machine, wait two hours, and then exit, you would find yourself emerging at a point in time two hours earlier than the time at which you entered the machine. Imagine then that Vincent plans to use this machine to travel back in time from $12.00 \mathrm{pm}$ to $6.00 \mathrm{am}$. When Vincent's wristwatch reads $11.55 \mathrm{am}$, he approaches the machine and looks through the open doorway. Inside he sees himself waving and wearing a wristwatch that displays the time $12.05 \mathrm{pm}$. As he watches, he notices that his counterpart is moving in reverse, and that this counterpart's watch is counting backwards towards $12.00 \mathrm{pm}$. At $11.59 \mathrm{pm}$ Vincent begins to walk towards the entrance of the time machine. At the same time, his counterpart (whose watch now reads $12.01 \mathrm{pm}$ ) begins to 'back' towards the same opening. The two Vincents reach the entrance just as their watches both read $12.00 \mathrm{pm}$.

\section{What happens next?}

The two Vincents merge, and then an instant later split again. Vincent continues to step into the time machine and begins to move backwards through time. He is now the counterpart that he has been observing up until this point. Indeed, if he were to look over his shoulder as he walked into the machine he would see his immediately prior self 'backing away' from the entrance, the watch of this counterpart counting back the minutes from $12.00 \mathrm{pm}$. When $12.05 \mathrm{pm}$ arrives, Vincent waves to the counterpart standing outside of the machine - a counterpart whose watch now reads $11.55 \mathrm{am}$.

Similar events occur at the other end of the journey. As Vincent's watch nears $6.00 \mathrm{pm}$, so too does his arrival at $6.00 \mathrm{am}$. When his watch reaches $5.59 \mathrm{pm}$ he looks out of the doorway to see a counterpart 'backing' towards the doorway. The watch of this counterpart reads $6.01 \mathrm{pm}$. As 6.00am nears, the two Vincents approach the doorway and as both of their watches read $6.00 \mathrm{pm}$ the two merge and split once again. Vincent walks away from the machine and - if he is to look over his shoulder - sees his counterpart 'backing' away from the doorway and into the machine - his watch ticking back the minutes from $6.00 \mathrm{pm}$. 
How would an external observer perceive this case of time travel? At 12.00pm they would witness the two Vincents (one approaching the door of the time machine from outside, the other 'backing' towards the doorway from inside the machine) merge. Immediately after this merging both Vincents would disappear, as $12.00 \mathrm{pm}$ is the point at which Vincent reverses his passage through time, meaning he is no longer present after this point in time.

If the external observer were around that morning they would be greeted with an even more unusual sight. At first they would find themselves observing an empty time machine. Then, at 6.00am, Vincent would appear on the threshold of the machine and separate into two individuals, one exiting the machine and carrying on as normal (having travelled six hours backwards through time), the other backing into the machine and remaining there (moving in reverse) for the next six hours.

As unusual as this story may be, it seems that we can (quite vividly) conceive of a possible world in which it takes place. Best of all, we seem perfectly capable of filling in all of the facts regarding Vincent's gradual backwards time travel journey through time and space. Such a story is therefore ideally conceivable.

\section{Conclusion}

We are capable of ideally conceiving of some backwards time travel journeys. Assuming the truth of the conceivability thesis, this means that some backwards time travel journeys are logically possible. While there may be many inconceivable (and, indeed, impossible) things that a time traveller is capable of doing upon arriving in the past, this does not mean that the time traveller is incapable of getting there in the first place. All instantaneous backwards time travel journey are ideally conceivable, so long as the time travel journey has as its destination a time and place that the time machine actually appeared. The conceivability of gradual backwards time travel is more limited. We cannot conceive of a time machine travelling backwards outside of time and space, so the machine must remain physically present at all times during its journey. In order to avoid the Double 
Occupancy Problem, however, we must imagine the machine working in a specific sort of way in order to ensure we can conceive ideally of such a journey. 


\section{Chapter 4 - Presentism and the Conceivability of Time Travel}

\section{Introduction}

In Chapter 1 of this thesis I put forward an argument for the conceivability of time travel. In Chapters 2 and 3 I expanded this argument to show that a number of different types of time travel are conceivable - including cases of both forwards and backwards time travel. If we assume the truth of the conceivability thesis, then the conceivability of these journeys entails their logical possibility.

In the process of conceiving of time travel, we also conceive of a number of other things: things that some metaphysical theories may hold to be impossibilities. Since conceivability entails possibility, it is better for our metaphysical theories to be informed by what is conceivable than vice-versa. In this way, I agree with Theodore Sider's argument that "the possibility of time travel limits the space of acceptable theories in [metaphysics and philosophy of science concerning the direction of time, causation and so on]. ${ }^{, 72}$ In the following two chapters I will discuss the implications of the conceivability of time travel for specific theories of time and causation.

\section{How the Conceivability Thesis Informs Our Metaphysical Views}

Suppose that we can conceive ideally of a particular case of time travel $C$. If the conceivability thesis is true (as we have assumed), then the following argument can be made:

1. If something is conceivable, then that thing is logically possible.

2. $C$ is conceivable.

\footnotetext{
72 Theodore Sider, 'Time Travel, Coincidences and Counterfactuals', Philosophical Studies 110 (2002) p. 115 .
} 
Therefore,

3. $C$ is logically possible.

Suppose, however, that some particular metaphysical theory $X$ is inconsistent with some state of affairs $S$. Suppose, further, that $S$ is entailed by $C$. If this is the case, then a proponent of $X$ might make the following argument:

1. $X$ is true.

2. If $X$ is true, then $\mathrm{S}$ is logically impossible

Therefore,

3. $S$ is logically impossible.

4. If $C$ is logically possible, then $S$ is logically possible.

Therefore,

5. $C$ is logically impossible

This conclusion is at odds with the conclusion of the conceivability argument above. I have argued, however, that what is conceivable should inform what we hold to be possible. Thus, in the tradition of one man's modus ponens being another man's modus tollens, the above argument can be inverted as follows:

1. $C$ is logically possible.

2. If $C$ is logically possible, then $S$ is logically possible.

Therefore,

3. $S$ is logically possible.

4. If $X$ is true, then $S$ is logically impossible.

Therefore,

5. $X$ is false.

As noted above, the conceivability argument provides evidence for the first premise. The argument in full, then, appears as follows:

1. If something is conceivable, then that thing is logically possible.

2. $C$ is conceivable. 
Therefore,

3. $C$ is logically possible.

4. If $C$ is logically possible, then $S$ is logically possible.

Therefore,

5. $S$ is logically possible.

6. If $X$ is true, then $S$ is logically impossible.

Therefore,

7. $X$ is false.

It may be of use to present a concrete analogy for how this argument works. Consider a parallel case: Imagine that 'four-wheelism' is the view that cars essentially possess four wheels - no more, no less. Suppose further that we wanted to disprove fourwheelism. In order to do this, we do not need to empirically discover a car with a different number of wheels, but merely rely on the conceivability of such a vehicle to disprove the notion that all cars must have four-wheels. Such an argument would appear as follows:

1. If something is conceivable, then that thing is also logically possible.

2. A five-wheeled car is conceivable.

Therefore,

3. A five-wheeled car is logically possible.

4. If a five-wheeled car is logically possible, then non-four-wheeled cars are logically possible.

Therefore,

5. Non-four-wheeled cars are logically possible.

6. If four-wheelism is true, then non-four-wheeled cars are logically impossible.

Therefore,

7. Four-wheelism is false.

This analogy should highlight how the conceivability thesis is similar to most other cases of counter-examples to particular philosophical arguments. Philosophers develop all sorts of general accounts, and these accounts have to be capable of handling all possible cases. Just like other cases of counter-examples then, the subject described (in this case, a five-wheeled car) does not need to actually exist - it merely needs to be conceivable. 
So too is it with metaphysical theories. If time travel is conceivable in the same way that five-wheeled cars are, then our metaphysical views must be capable of accommodating such journeys. If not, they must be abandoned.

\section{Presentism and Time Travel}

According to presentism only the present exists. ${ }^{73}$ The usual interpretation of presentism takes this to imply that travelling to other times is impossible. ${ }^{74}$ This is problematic. In the preceding chapters I have made out a clear case for the conceivability of at least some time travel journeys. The conceivability of any time travel journey - be it instantaneous or gradual, forwards or backwards - necessarily entails the conceivability of travel to the past or future. This is, by definition, exactly what time travel is. We cannot conceive of Vincent undergoing a forwards time travel journey without conceiving of him travelling to the future. Likewise, we cannot conceive of Vincent undergoing a backwards time travel journey without him travelling to the past. If some cases of time travel are conceivable (and therefore possible) so too is travel to other times. So long as one of these stories is conceivable, we will have proven the logical possibility of travel to other times.

In this chapter I will argue that the conceivability of time travel means the presentist must either modify their view of time to accommodate the possibility of time travel journeys or abandon presentism altogether.

\section{The Nowhere Argument}

Presentism is the view that: ${ }^{75}$

all reality is confined to the present - that past and future things simply do not exist, and that all quantified statements that seem to carry commitment to past or future things are either false or susceptible of paraphrase into statements that avoid the implication.

\footnotetext{
${ }^{73}$ Craig Bourne, A Future for Presentism (Oxford: Oxford University Press, 2006), p. 13.

${ }^{74}$ See, for example, Hales, op. cit..

${ }^{75}$ Dean W. Zimmerman, 'The A-Theory of Time, the B-Theory of Time, and 'Taking Tense Seriously", Dialectica Vol. 59, No. 4 (2005), p. 402.
} 
Ordinarily, presentists have a hard time making sense of time travel stories. Indeed, as Simon Keller and Michael Nelson note, the 'common view' is that "time travel is possible if the four-dimensional view of time is correct, but is not possible if presentism is true". 76

The presentist's difficulty arises from the supposed destinations of potential time travellers. Vincent, currently at $12.00 \mathrm{pm}$, plans to travel forward to $6.00 \mathrm{pm}$ or backward to 6.00am - but according to the presentist these destinations simply do not exist. So far as the presentist is concerned, $6.00 \mathrm{pm}$ is just like Tatooine. ${ }^{77}$ Neither is real, and we are just as incapable of travelling to one as we are the other. Put simply, "one cannot journey to the nonexistent, and so if presentism is true, then one cannot travel to nonexistent points in time, namely any time other than the present" ${ }^{78}$ This is what Keller and Nelson call the Nowhere Argument against time travel. For our purposes it is better to state the argument more formally. The Nowhere Argument, then, appears as follows: ${ }^{79}$

1. Presentism is true.

2. If presentism is true, then only the present exists.

Therefore,

3. Only the present exists.

4. It is logically impossible to travel to a time that does not exist.

Therefore,

5. Travelling to the past or future is logically impossible.

6. If time travel is logically possible, then so too is travelling to the past or future. Therefore,

7. Time travel is logically impossible.

What, precisely, does this argument mean for our ability to conceive of (at least some) time travel journeys?

\footnotetext{
${ }^{76}$ Keller and Nelson, op. cit., p. 334.

${ }^{77}$ That is, the fictional childhood home planet of Luke Skywalker in Star Wars: Episode IV - A New Hope, Dir. George Lucas, Lucasfilm, and Twentieth Century Fox Film Corporation, 1977.

${ }^{78}$ Hales, op. cit., p. 354.

${ }^{79}$ This is a restatement of Keller and Nelson's argument from Keller and Nelson, op. cit., pp. 334-335.
} 


\section{The Conceivability of Time Travel and the Somewhere Argument}

According to the Nowhere Argument, the truth of presentism means that time travel is impossible. Despite this, however, it is clear that we can conceive of travel to other times. Since we cannot conceive of something that is logically impossible, ${ }^{80}$ the Nowhere Argument must be flawed in some way.

Suppose that, as we did with the argument for four-wheelism, we use the possibility of time travel to turn the Nowhere Argument back on itself:

1. Time travel is logically possible.

2. If time travel is logically possible, then so too is travelling to the past or future. Therefore,

3. Travelling to the past or future is logically possible.

4. It is logically impossible to travel to a time that does not exist. Therefore,

5. The past and future exist.

6. If presentism is true, then only the present exists.

Therefore,

7. Presentism is false.

To be clear, the truth of the first premise is derived from the truth of the conceivability thesis combined with our assertion that at least one time travel journey is conceivable. The full argument, then, is as follows:

1. If something is conceivable, then that thing is also logically possible.

2. Time travel is conceivable.

Therefore

3. Time travel is logically possible.

4. If time travel is logically possible, then so too is travelling to the past or future. Therefore,

5. Travelling to the past or future is logically possible.

\footnotetext{
${ }^{80}$ A claim that underpins the conceivability thesis, and which I argued for in Chapter 1 (see above at p. 10).
} 
6. It is logically impossible to travel to a time that does not exist.

Therefore,

7. The past and future exist.

8. If presentism is true, then only the present exists.

Therefore,

9. Presentism is false.

I will henceforth refer to this as the Somewhere Argument. The argument is valid. Premise (1) will be true if we accept the truth of the conceivability thesis. Premise (2) will be true if we acknowledge that at least one time travel story is conceivable. Premise (3) is entailed by premises (1) and (2). Premise (4) is a fairly uncontroversial statement about what time travel entails. Premise (5) is entailed by (3) and (4). Premise (6), as we shall see, is the contentious claim. Premise (7) is entailed by (5) and (6). Premise (8) is merely a statement of presentism in its simplest form.

What reply might the presentist give to such an argument?

\section{Possible Presentist Replies to the Somewhere Argument}

The presentist's first objection might be to simply disagree with premise (1) and state that the conceivability thesis is false. As noted earlier, the conceivability thesis is the thesis that if something is conceivable, then it is also logically possible. The presentist may reject this claim, instead arguing that we can conceive of things that are logically impossible, and that the conceivability of something in no way entails its logical possibility. I will not provide a reply to that objection here. For the purposes of this thesis I have assumed the truth of the conceivability thesis. I gave some reasons for this assumption in Chapter $1^{81}$ and, in the absence of any counter-examples (that is, cases of logical impossibility which we are capable of conceiving of) it seems safe to assume that this thesis holds.

\footnotetext{
${ }^{81}$ See above at p. 10.
} 
Alternatively, the presentist might object to premise (2) by arguing that we are not actually conceiving of those time travel stories we discussed in Chapters 1,2 and 3. This is a bold claim. Granted, some cases of time travel are more difficult to conceive of than others (gradual backwards time travel, for example). Despite this, we can - and did conceive of at least some simple time travel journeys. It does not need to be the case that all time travel journeys are conceivable, nor that even all time travel journeys discussed in this thesis are conceivable. All the Somewhere Argument needs is one conceivable time travel journey, and it seems clear that we at least have this.

The best option for the presentist is to deny premise (6): that is, to deny that it is impossible to travel to a time that does not exist. This allows the presentist to maintain their core belief (that only the present exists) while allowing for the conceivability of time travel journeys. This, in a sense, is exactly what we should expect. If time travel is possible, then presentism must be compatible with such journeys in order to remain a plausible theory of time.

\section{Should Presentists Believe in Time travel?}

Simon Keller and Michael Nelson put forward an explanation of how presentists can make sense of stories containing travel to other (non-existent) times. ${ }^{82}$ It is not my intention to repeat that argument in its entirety. Instead, I will briefly explain how the presentist can use Keller and Nelson's approach to reject premise (6) of the Somewhere Argument and shore up their own theory of time in the face of conceivable time travel journeys.

In order to make their argument, Keller and Nelson focus on stories that are clearly cases of time travel and that seem to be compatible with a four-dimensional view of time. They then attempt to show that "if these stories really are compatible with fourdimensionalism, and presentism is at all plausible, then they are compatible with presentism too". ${ }^{83}$ To be clear, Keller and Nelson do not argue that all cases of time travel

\footnotetext{
${ }^{82}$ Keller and Nelson, op. cit..

${ }^{83}$ Ibid., p. 334.
} 
are possible on a presentist model of time - only some. Hopefully, however, the set of time travel stories that are compatible with presentism will include all of those time travel stories that are conceivable. If not, it will remain the case that there are some conceivable (and therefore possible) time travel stories for which the presentist cannot account, thus restoring force to the Somewhere Argument against presentism.

\subsection{Keller and Nelson's Criticism of the Nowhere Argument}

Keller and Nelson object to the Nowhere Argument on the ground that it simply proves too much. They note that if it were a good argument it would not only rule out time travel, but also our ordinary passage through time from one moment to the next: ${ }^{84}$

\footnotetext{
Consider what is about to happen to all of us. We are about to take a journey into the immediate future. Now it is over... We just travelled to a time that did not exist, and we are about to travel to a time that does not exist. If it were impossible to travel to times that do not exist, then we would not be able to make these journeys in time, and the ordinary passage of time from one moment to the next would be impossible.
}

Where the argument goes wrong, they allege, is in its statement that it is impossible to travel to a time that does not exist. The presentist, then, can use Keller and Nelson's argument to disagree with premise (6) of the Somewhere Argument, thus avoiding the conclusion that presentism is false.

\subsection{Travelling to Non-existent Times}

Of all of the time travel stories discussed in this thesis, it would seem that the most clearly conceivable is Vincent's first (instantaneous) foray into the future. Consider again VS1:

VS1: Vincent has built a time machine. Vincent steps into the machine at $12.00 \mathrm{pm}$ on Wednesday $1^{\text {st }}$ January 2020 . He sets the destination time on the machine's control panel to

\footnotetext{
${ }^{84}$ Ibid., p. 335.
} 
“6.00pm Wednesday $1^{\text {st }}$ January 2020" and presses the 'On' button. The machine disappears. At $6.00 \mathrm{pm}$ that same day the machine reappears. The physical going on within Vincent and the time machine are now exactly as they would have been immediately after Vincent pressed the 'On' button at $12.00 \mathrm{pm}$ if he had not in fact pressed the button. Vincent exits the time machine (conveniently located in his garage) and goes into his living room. Once there, he makes a cup of tea and turns on the television to watch the six o'clock news.

The conceivability of this story entails its possibility. How, then, can the presentist make sense of this journey without compromising their position that only the present exists?

As Keller and Nelson note, while presentists believe that the past and future do not exist, they usually do not "go so far as to say that there are no past- or future- tensed truths." ${ }^{, 85}$ A presentist can, for example, say that it is true that a Democratic candidate won the U.S. Presidential Election in 2008, just as they can say that it is true that a U.S. Presidential Election will be held in $2012 .{ }^{86}$ Presentists can also make past- and futuretensed truths about presently existing entities. They can, for example, say that it is true that Barack Obama was elected as President of the United States of America in 2008, just as we can say it is true that one day he will no longer be President.

It is the presentist's ability to make truth claims about the past and future that provides the foundation for presentist time travel. It does not matter how the presentist accounts for past- and future- tensed truths, it is enough that presentists are capable of doing this somehow. ${ }^{87}$ If we assume that presentists can make truth claims about the past and future then it is clear that they can describe many of same time travel stories as the four-dimensionalist. As Keller and Nelson note: ${ }^{88}$

The point is that all the details that featured in the four-dimensionalist story can be included in the presentist story too, so long as they are expressed as tensed truths properly relativised to the present. Four-dimensional time travel is possible because it is possible that there are the right sorts of patterns of events.

\footnotetext{
${ }^{85}$ Ibid., p. 337.

${ }^{86}$ Assuming, of course, that such an election does happen in order to make this a future-tensed truth.

${ }^{87}$ Keller and Nelson, op. cit., p. 337.

${ }^{88}$ Ibid., p. 338.
} 
Four-dimensional time travel simply requires that certain events happen at certain times. When conceiving of Vincent's various journeys we made lists of these events. Lists like:

1. Vincent and his time machine disappear at $12.00 \mathrm{pm}$ on Wednesday $1^{\text {st }}$ January 2020.

2. Vincent and his time machine appear at $6.00 \mathrm{pm}$ on Wednesday $1^{\text {st }}$ January 2020.

3. Upon appearing, Vincent is able to exit his time machine and physically interact with the world around him.

4. Upon appearing, Vincent's immediately prior experience is of having pressed the 'On' button in his time machine at $12.00 \mathrm{pm}$ on Wednesday $1^{\text {st }}$ January 2020.

According to Keller and Nelson, all of these events are just as capable of being described on a presentist view of time. VS1 is initially described in four-dimensional terms, but there is nothing preventing a translation of this story into presentist terms. Consider the following retelling of the story:

VS1(P): It is $12.00 \mathrm{pm}$ on Wednesday $1^{\text {st }}$ January 2020. Vincent has built a time machine. Vincent is now stepping into the machine. Once he is in the time machine, he will set the destination time on the machine's control panel to "6.00pm Wednesday $1^{\text {st }}$ January 2020" and press the 'On' button. Immediately after Vincent presses the button, he and the machine will disappear. At $6.00 \mathrm{pm}$ today the machine will reappear. The physical processes going on within Vincent and the time machine will be exactly as they would have been immediately after Vincent pressed the 'On' button at $12.00 \mathrm{pm}$ if he had not in fact pressed the button. Vincent will exit the time machine (conveniently located in his garage) and go into his living room. Once there, he will make a cup of tea and turn on the television to watch the six o'clock news.

If we are slightly more ambitious, we can even attempt a retelling of Vincent's instantaneous backwards time travel story:

VS6(P): It is $12.00 \mathrm{pm}$ on Wednesday January $1^{\text {st }} 2020$. Vincent has built a time machine.

Vincent is now stepping into the machine. Once he is in the time machine, he will set the 
destination time on the machine's control panel to "6.00am Wednesday January $1^{\text {st }} 2020$ " and press the 'On' button. Immediately after Vincent presses the button, he and the machine will disappear. At 6.00am Wednesday January $1^{\text {st }} 2020$ the machine appeared. The physical processes going on within Vincent and the time machine were exactly as they will be immediately after Vincent presses the 'On' button at $12.00 \mathrm{pm}$ if he does not in fact press the button. Vincent exited the time machine (conveniently located in his garage) and went into his living room. Once there, he made a cup of tea and turned on the television.

In this way, we can retell both forwards and backwards instantaneous time travel stories in presentist terms.

It is unclear whether our conceivable case of gradual backwards time travel can be restated in this way. Perhaps this is one of those stories that Keller and Nelson note as particularly problematic for presentists - stories containing closed timelike curves. ${ }^{89}$ I will not discuss this case. It is not my intention to provide a full defence of presentism here, but rather to point out one way in which the presentist might respond to the conceivability of time travel stories. If presentism a plausible theory of time, then it must be able to make sense of all of those time travel stories we find to be conceivable.

\subsection{Presentist Time Travel and Personal Identity}

Presentist time travel relies on our ability to restate the facts of a four-dimensional time travel journey in presentist terms. As shown above, it seems clear that we are able to do this with Vincent's instantaneous time travel journeys. There is an underlying assumption in Vincent's stories that we have not yet considered, however: namely, that the Vincent who appears at the destination time is the very same Vincent who disappears at the departure time. Personal identity is the lynchpin for any credible time travel story. If we cannot show that the person appearing in the past or future is the very same person as the one who disappears in the present, then we don't really have a time travel story, but rather a story of random appearances and disappearances of persons. We must therefore examine

\footnotetext{
${ }^{89}$ Keller and Nelson, ibid, Footnote 5. However Bradley Monton argues for the presentist retelling of even these sorts of stories in Bradley Monton, 'Presentists can believe in closed timelike curves', Analysis, Vol. 63, No. 3 (July 2003), pp. 199-202.
} 
whether the facts which make a time traveller the very same person can be translated into presentist terms.

What is it that makes the Vincent who disappears the very same Vincent who reappears in our four-dimensionalist time travel stories? As Keller and Nelson note, there are various views. We might hold that the two Vincents are the same person "because they are parts of the same causal chain; ...because they share a soul; ...because they have the same brain; ...the same body; [or] because they are psychologically continuous." 90 Whatever our particular theory of personal identity may be, we will acknowledge that there is some relation (call this the $R$-relation) that is sufficient for personal identity and that is capable of holding between discontinuous person stages. Without this, we cannot have even four-dimensional time travel stories.

According to Keller and Nelson any $R$-relation which holds on a four-dimensional time travel story should be just as capable of holding on a presentist time travel story. There is no special problem of personal identity for presentist time travel. Put simply: "if the four-dimensionalist can get away with saying that [discontinuous person stages] are all the same person, then the presentist can too." ${ }^{91}$ Suppose we adopt the following $R$-relation:

"A is identical to B iff A remembers being B, or B remembers being A."

The Vincent who appears clearly remembers being the Vincent who disappeared, as evidenced by the fact that "upon appearing, Vincent's immediately prior experience is of having pressed the 'On' button at $12.00 \mathrm{pm}$ on Wednesday $1^{\text {st }}$ January 2020 ". ${ }^{92}$ On the above $R$-relation then, the Vincent who appears is the very same person as the Vincent who disappears. The same will remain true regardless of whether the facts of Vincent's story are expressed in four-dimensional or presentist terms. In this way, then, the $R$-relation holds, regardless of what view of time is adopted.

\footnotetext{
${ }^{90}$ Keller and Nelson, op. cit., pp. 339.

${ }^{91}$ Ibid.

92 Assuming, of course, that Vincent's journey through time has not caused some inexplicable case of amnesia.
} 


\title{
7.4 Presentist Time Travel as Suicide
}

Steven Hales disagrees, believing that "there is still a remaining conundrum for the would-be presentist time traveller, one that cannot be resolved through the clever manipulation of tensed sentences". ${ }^{93}$ Hales argues that, for presentists, an instantaneous time travel journey is simply suicide: ${ }^{94}$

\begin{abstract}
Recall that presentists are committed to a purely objective present; the events and objects at this objective present alone are real, even if other things have been or will be real. After entering the time machine, [the time traveller] no longer exists in the objective present, and therefore he is no longer in reality. Which is just to say that [the time traveller] ought to view the time machine with considerable trepidation - after all, it means his annihilation.
\end{abstract}

On this view, then, when Vincent presses the 'On' button in his time machine, he causes himself to cease to exist in the objective present. That is, he causes himself to cease to exist at all.

According to Hales, permanent time travel to the past means death for Vincent. ${ }^{95}$ This is a concept explored in the Doctor Who episode 'Blink', ${ }^{96}$ where fictional antagonists known as the Weeping Angels kill their victims "in the nicest way possible" - namely by sending them far back in time to live out the rest of their lives. Consider also what happens at the other end of the time travel journey: ${ }^{97}$

\footnotetext{
Not only does presentist "time travel" merely require the would-be traveller to go out of existence in nihilum, but it also requires that objects come into existence ex nihilo. When [the time traveller] steps into the time machine in 2010 and pushes the buttons for 399 $\mathrm{BCE}$, the time machine causes it to be the case that in $399 \mathrm{BCE}$, [the time traveller] came into existence. But he literally came into existence out of nothing.
}

\footnotetext{
${ }^{93}$ Hales, op. cit., p. 356.

${ }^{94}$ Ibid., p. 357.

95 Ibid.

96 'Blink', Doctor Who, Season 3, Episode 10, Dir. Hettie MacDonald, British Broadcasting Corporation (BBC), 2007.

${ }^{97}$ Hales, op. cit., p. 358.
} 
So, Hales argues, a presentist account of time travel not only results in the death of a time traveller, but also leads to strange appearances out of nowhere.

Even more unusual is what happens when Vincent travels forward in time. If he travels six hours into the future then he will go out of existence at $12.00 \mathrm{pm}$, and come back into existence six hours later. In cases like this, time travel into the future is best described as "death and resurrection of the body". 98

I do not see how either of these cases is particularly problematic for presentist time travel. While they do present some unusual results of time travel stories told on presentist terms, they do not in any way demonstrate the impossibility of such journeys.

The notion that backwards time travel is equivalent to 'death' on a presentist view of time is simply mistaken. In order to see this, it is important to refer to Lewis' concepts of personal and external time. ${ }^{99}$ Personal time is that measured from the perspective of the time traveller (say by his exceptionally reliable wristwatch), while external time is that measured by the 'rest-of-the-world' (say by the Greenwich Mean Time Clock). ${ }^{100} \mathrm{~A}$ person, then, is a collection of consecutive person stages. These stages should be ordered according to the personal time of the individual, though the stages may in fact be located at very distant or unordered points in external time. Death is what occurs to the very last person-stage identified by any particular $R$-relation - that is, the person stage which is followed by no further person stages. If there is, was, or will be some person stage which exists - in personal time - after Vincent's current person stage, then Vincent will not die when he presses the 'On' button. Suppose we adopt the $R$-relation from before: that is, the $R$-relation which states that " $\mathrm{A}$ is identical to $\mathrm{B}$ iff $\mathrm{A}$ remembers being $\mathrm{B}$, or $\mathrm{B}$ remembers being A." If there is some person stage which will remember being Vincent at $12.00 \mathrm{pm}$ then, on this account of personal identity, Vincent will not die at $12.00 \mathrm{pm}$. It does not particularly matter when (or where) that next person stage is located.

\footnotetext{
${ }^{98}$ Ibid., p. 357.

${ }^{99}$ Lewis (1987), op. cit., p. 69.

${ }^{100}$ Though Lewis notes that we should avoid defining external and personal time operationally as devices such as wristwatches are not infallible (ibid., p. 69).
} 
All Hales has done is to exaggerate a number of general anxieties we have regarding discontinuous person stages. Any misgivings we had about pressing the 'On' button of an instantaneous time travel machine would arise from the temporal discontinuity that was about to occur in our person, regardless of whether we did this on a fourdimensional or presentist view of time. If we are wary of discontinuities in our personhood, then we should be just as wary of four-dimensional instantaneous time travel as we are presentist instantaneous time travel. We should also feel equally uncomfortable about any other potentially discontinuity-causing technologies such as teletransportation. Presentist time travel, then, is not 'suicide' - at least, no more so than any other discontinuity-causing journey is.

\section{Conclusion}

If presentism is to remain a plausible theory of time, then it must have a way of accommodating those time travel stories which are conceivable, and thus possible. The best way for the presentist to do this is to restate conceivable time travel stories in presentist terms. By doing this, the presentist maintains their belief that only the present exists, while also allowing for the possibility of some time travel stories. 


\section{Chapter 5: Causation and the Conceivability of Time Travel}

\section{Introduction}

Our ability to conceive of a number of different cases of time travel entails the conceivability of two particularly unusual types of causal relationship. In this chapter I will describe these types of causal relationships, and the implications of their conceivability for which views of causation we choose to adopt.

\section{Causation at a Distance}

When we conceive of cases of instantaneous time travel (be it forwards or backwards) we also conceive of causation at a distance - that is, some cause $C$ bringing about some effect $E$ at an earlier ${ }^{101}$ or later time, even though $C$ and $E$ are at a temporal distance. Why is this unusual? It certainly seems that we already experience causation at distance on a regular basis. Every night before bed I set my alarm clock to go off the following morning, and this cause (setting the alarm) leads to an effect (my alarm going off) many hours later. Is this not causation at a distance? While it may appear that this cause and effect are located at a temporal distance, they are in fact linked by a "chain of causal dependence that links the two events across time". ${ }^{102}$ In setting the alarm, I initiate a causal chain of digital programming which will eventually result in the sounding of my alarm the following morning. This causal chain closes the apparent causal distance between cause and effect.

The same cannot be said of instantaneous time travel. In order to conceive ideally of Vincent's instantaneous forwards time travel journey, we had to imagine a world in which four facts held:

\footnotetext{
${ }^{101}$ It is worth noting that such an occurrence would also be problematic for the reason stated in Part 3 of this chapter - namely, that it requires backwards causation.

${ }^{102}$ Keller and Nelson, op. cit., p. 340.
} 
1. Vincent and his time machine disappear at $12.00 \mathrm{pm}$ on Wednesday $1^{\text {st }}$ January 2020 .

2. Vincent and his time machine appear at $6.00 \mathrm{pm}$ on Monday $1^{\text {st }}$ January 2120.

3. Upon appearing, Vincent is able to exit his time machine and physically interact with the world around him.

4. Upon appearing, Vincent's immediately prior experience is of having pressed the 'On' button at $12.00 \mathrm{pm}$ on Wednesday $1^{\text {st }}$ January 2020.

It is true that there is nothing in these facts that states that Vincent's appearance was caused by his disappearance, nor that his memories at $6.00 \mathrm{pm}$ were caused by the events prior to his disappearance at $12.00 \mathrm{pm}$. Causation, however, is implicit. In order for this to be a genuine case of time travel, the Vincent who appears at $6.00 \mathrm{pm}$ must be the very same Vincent who disappears at $12.00 \mathrm{pm}$. If this is the case, then the memories that Vincent possesses at $6.00 \mathrm{pm}$ must have been caused by the events that occurred prior to $12.00 \mathrm{pm}$.

Unlike the case of my alarm clock, however, a case of instantaneous time travel involves the time machine and time traveller being located nowhere and nowhen during their journey. When Vincent's time machine travels from $12.00 \mathrm{pm}$ to $6.00 \mathrm{pm}$ it skips over the six hours in between. There is no chain of causal dependence linking its disappearance to its reappearance as there was linking the setting of my alarm at night to its going off in the morning. A case of instantaneous time travel is thus a much clearer example of causation at a distance. $C$ (the disappearance of the time machine) causes $E$ (the appearance of the time machine) despite the two events being at a temporal distance and having no linking chain of causal dependence to bridge this gap.

The conceivability of instantaneous time travel entails the logical possibility of causation at a distance. Any plausible view of causation must, therefore, be able to account for such cases of causation. There is, however, a far more troubling implication of the conceivability of time travel for our views of causation. 


\section{Backwards Causation}

Our ability to conceive of time travel necessarily involves an ability to conceive of causation moving in whatever direction the time traveller is travelling. This is not a problem in the case of forwards time travel, as causation continues to run in the normal direction: that is, causes precede effects and effects follow causes. Cases of backwards time travel are more problematic. In these cases, effects can precede causes and causes follow effects.

In order to conceive ideally of Vincent's instantaneous backwards time travel journey, we had to be capable of coherently imagining a world in which four facts held:

1. Vincent and his time machine disappear at $12.00 \mathrm{pm}$ on Wednesday $1^{\text {st }}$ January 2020.

2. Vincent and his time machine appear at 6.00am Wednesday $1^{\text {st }}$ January 2020

3. Upon appearing, Vincent is able to exit his machine and physically interact with the world around him.

4. Upon appearing, Vincent's immediately prior experience is of having pressed the 'On' button in his time machine at $12.00 \mathrm{pm}$ on Wednesday $1^{\text {st }}$ January 2020.

In this case, Vincent carries out backwards causation by merely arriving in the past - that is, by having his disappearance in the future as the cause of his appearance in the past. It is true that nowhere in these facts is it made explicit that Vincent's disappearance at $12.00 \mathrm{pm}$ causes his appearance at $6.00 \mathrm{am}$. However, as stated above, this causation should be implicit. If Vincent's disappearance at $12.00 \mathrm{pm}$ did not cause his appearance at $6.00 \mathrm{am}$ then we are not, in fact, dealing with a time travel story at all.

For the purposes of this argument, however, I will focus on cases of gradual backwards time travel, as in these cases backwards causation is far more apparent. Consider the version of Vincent's story which described the time machine as a room in which time ran backwards at a ratio of 1:1. Suppose that, just before departing, Vincent was overcome with a tremendous appetite, so pocketed an apple for a snack on his 
impending journey. Once he has entered the machine (and begun his journey back in time) he begins to eat the apple. On this story, the following would be true:

1. Vincent's hunger at $12.00 \mathrm{pm}$ is a cause of Vincent having an apple in his pocket at 11.55am.

2. Vincent having an apple in his pocket at $11.55 \mathrm{am}$ is a cause of Vincent eating an apple at 11.30am.

3. Vincent eating an apple at 11.30am is a cause of Vincent having an apple core in his pocket at 11.00am.

We stated above that backwards causation will have occurred where the time machine and time traveller simply appear in the past. It is clear, however, that in cases of gradual backwards time travel the time traveller does not even have to get this far. As soon as the time traveller begins to move backwards in time there is backwards causation.

It is clear then that our ability to conceive of gradual backwards time travel also entails an ability to conceive of backwards causation. What does the conceivability of backwards causation mean for our ordinary views of causation? Before answering this question, it may be useful first to outline a common view of the direction of causation.

\section{Mellor's View of Causation}

As D.H. Mellor notes, the most striking difference between the past and the future is that "we can see... what is past, but cannot affect it", whereas with the future "we can

affect it, but not see it". ${ }^{103}$ This distinction is a result of the direction of causation. Causes precede effects, and effects follow causes. My experiences of an event are an effect, the cause of which is the event itself. For this reason I cannot see what lies in the future. Likewise, my actions are causes, the effects of which will occur later. For this reason I cannot affect what is past.

${ }^{103}$ Mellor, op. cit., p. 105. 
In our ordinary experiences causation continually runs in a forward direction. It seems, however, that the tendency of causation to always run in the same direction is far more than a coincidence. Indeed, the direction of causation does not seem contingent, but rather "absolute and unchanging". ${ }^{104}$ What, then, explains this?

There is clearly a link between causal order and temporal order, with causes occurring earlier than their effects, and effects occurring later than their causes. Mellor argues that it cannot be the case that the causal order and the temporal order are completely independent as, if this were so, it would be "as conceivable that effects generally precede their causes as that causes generally precede their effect". ${ }^{105}$ Perhaps then, causal order simply matches up with temporal order, and we may define a cause "as the earlier of two causally related facts or events". ${ }^{106}$ According to Mellor, however, this simply will not do. This is due to the fact that: ${ }^{107}$

\footnotetext{
There are at least two other ways of distinguishing causes from effects with which this definition could conflict. These follow from the fact that whereas causes both explain their effects and provide means of bringing them about, effects neither explain nor provide means of bringing about their causes.
}

Vincent's hunger and possession of a delicious apple explain and provide a means of bringing about the fact that he has an apple core in his pocket. The opposite is not true. The fact that Vincent has an apple core in his pocket does not explain or provide a means of bringing about the fact that he is hungry and possesses a delicious apple.

While it is useful to use the notions of explanation and means to pick out the cause in any pair of causally related facts, it does not explain why this definition continually picks out the earlier fact of any given pair. Put simply, it does not explain the continually observed relationship between causes and effects, and earlier and later times. The fact that "we cannot reduce the causal order of facts and events to their temporal order" ${ }^{108}$ leads Mellor to believe that the reduction should operate in the opposite way. That is, that

\footnotetext{
104 Ibid.

${ }^{105}$ Ibid., p. 107.

106 Ibid.

107 Ibid.

${ }^{108}$ Ibid., pp. 107-108.
} 
temporal order relies on causal order. He argues that "if the general coincidence of causal and temporal order is to be more than a coincidence, it cannot be because time order fixes causal order. It must be the other way around."109

\section{Backwards Causation on Mellor's View of Causation}

What then, does our ability to conceive of backwards causation mean for Mellor's view of causation? On first gloss, it seems that there is no problem. Mellor himself even acknowledges the "apparent possibility... of backward causation" ${ }^{110}$ on a view which reduces temporal order to causal order.

Indeed, Mellor's view of the relationship between time and causation makes our job much easier. Many of the problems with backward causation arise from the way in which it apparently runs counter to the flow of time: specifically, the way in which it allows causes to be later than effects. On Mellor's view, however, we can begin with our conception of a case of backwards causation and then, from this, draw conclusions regarding the direction of time in that story. Causes will still precede effects, and effects follow causes. Recall Vincent's gradual backwards time travel journey. We were able to conceive ideally of this journey by coherently imagining a possible world in which there existed a machine in which all causal processes ran backwards. On Mellor's view of the relationship between time and causation this machine is - by definition - simply a region of space in which time runs counter to the direction it runs elsewhere.

There is nothing problematic about this. Our ability to conceive ideally of cases of gradual backwards time travel simply shows an ability to conceive of regions of space in which the causal order - and therefore the temporal order - runs in a different direction to its direction in other regions. Indeed, even referring to this as 'backwards' causation is somewhat parochial. Who is to say that the direction of time in our particular region of space is necessarily 'forwards'? To the backward-travelling time traveller looking out of

\footnotetext{
${ }^{109}$ Ibid., p. 108.

${ }^{110}$ Ibid., p. 113.
} 
his time machine's window, it would appear that the rest of the world is undergoing backwards causation, while he alone is moving forwards.

It might be argued that the very notion of backwards time travel implicitly requires some objective direction of time according to which the time traveller can travel 'backward'. Such a direction may be established by doing as Lewis does and observing the direction in which counterfactual dependence - and thereby causation - tends to run. ${ }^{111}$ If temporal order is defined by causal order (a point that I have not - and do not plan to contest), then this would be a way of establishing in which regions of space time runs in the 'normal' direction and in which regions time runs counter to this.

I do not, however, believe that we even need to go this far. As we have defined it, time travel merely requires some discrepancy between the duration of a time traveller's journey and the period of time he has traversed. This requirement can be met simply by transferring from a region of space where time runs in one direction to a region of space in which it runs in the opposite direction. If this is done, then a time discrepancy will have occurred. No appeal to an objective 'forwards' direction of time is required.

It is clear then that, on an account of causation which defines temporal order as causal order, backwards causation is entirely possible.

\section{Mellor's Objections to Backwards Causation}

Despite the apparent compatibility of backwards causation with this theory of causation, Mellor objects to its possibility.

\footnotetext{
${ }^{111}$ David Lewis, 'Counterfactual Dependence and Time's Arrow', Noûs, Vol. 13, No. 4, Special Issue on Counterfactuals and Laws (November 1979), pp. 455-476.
} 


\subsection{Mellor's First Objection}

While there is nothing problematic in having different causal (and therefore temporal) directions in different regions of space, a problem does seem to arise when something moves from one region to another - just as Vincent does when he exits his machine at his temporal destination of 6.00am. Throughout the time travel journey, causes continue to occur before their effects. This is trivially true, as the temporal ordering of 'before' and 'after' is defined by the causal order. There is, for example, nothing problematic about the following two facts of Vincent's journey:

1. Vincent having an apple in his pocket at $11.55 \mathrm{am}$ is a cause of Vincent eating an apple at 11.30am.

2. Vincent eating an apple at 11.30am is a cause of Vincent having an apple core in his pocket at 11.00am.

While these facts may seem unusual, it is only because we have ascribed times to these events based upon the times given in an adjacent region of space where causal processes are running counter to those in the machine. The above two causally related facts are therefore better described as follows:

1. Vincent having an apple in his pocket five minutes into his journey is a cause of Vincent eating an apple thirty minutes into his journey.

2. Vincent eating an apple thirty minutes into his journey is a cause of Vincent having an apple core in his pocket sixty minutes into his journey.

Such a description is unproblematic, as causes continue to precede their effects. This is because all causally related events are occurring within a region of space (Region A) in which all causal processes run in the same direction. Effects might appear to precede causes as viewed from some other region of space, but as noted above, this is mere parochialism. Effects precede causes in Region A no more than effects precede causes in our region as viewed by those in Region A. Temporal direction relies on causal direction, so it makes no sense to order events in Region A according to the causal direction of our own region. 
Problems arise, however, when something passes from a region of one causal direction to a region of a different causal direction. In these cases it becomes true that, on Mellor's view of causation, effects can precede their causes.

Mellor, however, strongly disagrees with the claim that an effect can precede its cause. He illustrates this by raising a common objection to backwards time travel: the infamous Grandfather Paradox. ${ }^{112}$ This is the paradox that says that, if backwards causation is possible (ordinarily in the form of time travel), then it would be possible for an individual to take certain actions which would result in the death of his or her grandfather. Since doing this would result in a clear contradiction, ${ }^{113}$ backwards causation must be logically impossible.

Mellor discusses several unsatisfactory replies to the Grandfather Paradox before settling on David Lewis' consistency requirement as the best solution to the problem. This is the requirement that a time traveller simply will not do something which was not in fact done (such as causing his own grandfather to be killed before fathering any children). ${ }^{114}$ The very existence of the time traveller clearly shows that he did, and therefore will, fail in any such attempt. The reasons for this could be many: "perhaps some noise distracts him at the last moment, perhaps he misses despite all his target practice, perhaps his nerve fails, perhaps he even feels a pang of unaccustomed mercy."

Mellor disagrees with Lewis' solution, arguing that there is still a very real sense in which a time traveller could do something contradictory. ${ }^{116}$ According to Mellor, the response given by Lewis "overlooks the existence of real contingent possibilities". ${ }^{117}$ Mellor rightly notes that there are things the time traveller could do in the past, but which (on Lewis' view) he will not do as “it is necessarily impossible for [the time traveller] to do anything that would make his time travel tale inconsistent". ${ }^{118}$ According to Mellor

\footnotetext{
${ }^{112}$ Mellor, op. cit., p. 127.

${ }^{113}$ As this would lead to two contradictory facts being true: namely, that the time traveller's grandfather both did and did not die at that point in time.

${ }^{114}$ Lewis (1987), op. cit., p. 76.

115 Ibid.

${ }^{116}$ Ibid., p. 128.

${ }^{117}$ Ibid.

${ }^{118}$ Ibid.
} 
however, "nothing can be contingently possible that is necessarily impossible", and for this reason stories containing backwards causation must be logically impossible. ${ }^{119}$

Since backwards time travel necessarily entails this sort of causation, Mellor believes that backwards time travel must also be logically impossible.

\subsection{Responding to Mellor's First Objection}

As has been argued throughout this thesis, conceivability entails possibility. The fact that we can conceive of Vincent's backwards time travel journey is very good evidence for the logical possibility of such a journey. Backwards time travel entails backwards causation, suggesting that that this, too, is logically possible. If this is so, then Mellor's argument for the logical impossibility of backwards causation (and, by virtue of this, the logical impossibility of backwards time travel) must be flawed in some way. The fact that we are quite capable of ideally conceiving of cases of backwards time travel should give us good reason to reject Mellor's argument that all backwards time travel journeys are logically impossible.

Mellor's argument fails for two reasons. Firstly, he falls into the very trap that Lewis warns against. Mellor states that the contradiction in the Grandfather Paradox arises from the fact that something - namely, killing one's own grandfather - is both contingently possible and logically impossible. As Lewis explains, however, such a contradiction is based on an equivocation regarding what a time traveller can do. To say that killing one's grandfather is contingently possible is to say that the time traveller can kill his grandfather because he has what it takes. To say that killing one's grandfather is necessarily impossible is to say that the time traveller cannot kill his grandfather because it is logically impossible to change the past. ${ }^{120}$ According to Lewis, there is no contradiction in holding both of these facts to be true. They are "compatible because 'can' is equivocal". ${ }^{121}$ According to one "fairly rich" 122 set of facts - namely, a set of facts regarding how well-

\footnotetext{
${ }^{119}$ Ibid.

${ }^{120}$ Lewis (1987), ibid., p. 77.

${ }^{121}$ Ibid.

122 Ibid.
} 
motivated, well-trained, well-informed, and well-armed the time traveller is - the time traveller can clearly kill his or her grandfather. According to another more inclusive set of facts, however - namely a set of facts which includes the important fact that the time traveller's grandfather did not die before fathering any children - the time traveller cannot kill his or her grandfather. As Lewis notes: ${ }^{123}$

\footnotetext{
You can reasonably choose the narrower delineation, and say that he can; or the wider delineation, and say that he can't. But choose. What you mustn't do is waver, say in the same breath that he both can and can't, and then claim that this contradiction proves that time travel is impossible.
}

Mellor's view that backwards causation allows for something which is contingently possible to be necessarily impossible is thus based on an equivocation. If we are clear about what 'can' is taken to mean (and most importantly, what facts are to be considered) then no contradiction is apparent.

The second way in which Mellor's argument fails is that it is essentially the same old objection in new packaging. Mellor does have his own views about the determinants of the direction of time, but - like others before - he argues from the logical impossibility of certain actions which a time traveller might try to commit upon arriving in the past (such as killing his or her own grandfather) to the logical impossibility of backwards time travel journeys. My reply to this objection is the same as that I gave in Chapter 3. ${ }^{124}$ While it may be logically impossible for someone to travel back in time and prevent their own existence, successful backwards time travel journeys do not necessarily entail these sorts of scenarios. Our conception of a case of backwards time travel does not require us to conceive of someone creating this paradox.

Mellor's first objection to backwards causation once again distracts us from the real issue at hand: the conceivability - and thereby logical possibility - of time travel journeys. There are many impossible things that the time traveller might do upon arriving in the past, just as there are many impossible things I might do upon arriving at any other temporal or spatial destination. This does not, however, refute the possibility of the journey in the first

\footnotetext{
123 Ibid.

${ }^{124}$ See above, at page 42 .
} 
place. As Sider notes, "the impossibility of a certain kind of time travel scenario does not impugn the possibility of time travel in general". ${ }^{125}$ The time traveller does not need to engage in activities which might result in contradictions. All he needs to be able to do is arrive in the past, something that will be possible so long as it was the case that he arrived in the past.

\subsection{Mellor's Second Objection}

Mellor acknowledges two other potential problems with his conclusion regarding the Grandfather Paradox, namely: ${ }^{126}$

1. That it rests on the controversial assumption that there are contingent facts about what is possible at a time, as well as about what is actual.

2. That it does not tell us what these contingent possibilities have to do with causation, and so with backward causation and time travel.

Mellor attempts to remedy these problems by restating his objection to backwards causation. It seems, however, that this is better treated as a separate objection altogether.

Mellor's objection is based on two presuppositions. Firstly, Mellor presupposes that "every effect has chances with and without its causes". ${ }^{127}$ Secondly, Mellor presupposes the law of large numbers, ${ }^{128}$ that is, the law that states that the frequency of some event will closely reflect its probability of occurrence. For example, if I buy one hundred raffle tickets, each of which has a one-in-ten (0.1) chance of winning, then I can assume that the total number of winning tickets I have will be approximately ten (one-tenth of one hundred). Mellor uses these two assumptions to build an argument against the logical impossibility of backwards causation. He does this by taking effects which precede their causes to the next step - closed causal loops.

\footnotetext{
125 Sider, op. cit., p. 115.

${ }^{126}$ Mellor, op. cit., p. 128.

${ }^{127}$ Ibid., p. 129.

${ }^{128}$ Ibid., p. 133.
} 
Causal loops are often used as a basis for arguing against the possibility of backwards time travel. The simplest of these arguments is the Knowledge Paradox. Consider the following story: ${ }^{129}$

\begin{abstract}
An art critic from the future visits a $20^{\text {th }}$-century painter, who is regarded in the critic's own century as a great artist. Seeing the painter's current work, the critic finds it mediocre and concludes that the artist has yet to produce those inspired paintings that so impressed future generations. The critic shows the painter a book of reproductions of these later works. The painter contrives to hide this book, forcing the critic to leave without it, and then sets about meticulously copying the reproductions onto canvas. Thus, the reproductions exist because they are copied from the paintings, and the paintings exist because they are copied from the reproductions.
\end{abstract}

This is a troubling story, as the artist's work seems to appear from nowhere. It is, to use David Deutsch and Michael Lockwood's term, "a kind of artistic 'free lunch", 130 There is no end to the range of unusual causal loops authors are capable of creating. In The Case of Jocasta Jones ${ }^{131}$ a time traveller is able to father himself, while in All You Zombies $^{132}$ the time traveller - through a combination of time travel and gender reassignment - is able to become his own father and his own mother.There is no doubt that these sorts of stories are incredibly unusual, and it is difficult to imagine how such a chain of events might even get started. Despite this, however, there is nothing contradictory about them. They are not logically impossible states of affairs. Why, then, does Mellor believe that they are?

In order to effectively explain Mellor's argument, I will provide my own example of a very simple causal loop in which only two causal factors are present, each being both the cause and the effect of the other. Suppose that one of these causal factors is "having a high-paying job" $(A)$ and the other is "being a member of a privileged socio-economic group" $(B)$ :

\footnotetext{
${ }^{129}$ This is a retelling of Michael Dummett's original story by David Deutsch and Michael Lockwood in David Deutsch and Michael Lockwood, 'The Quantum Physics of Time Travel', in Susan Schneider (ed.) Science Fiction and Philosophy - From Time Travel to Superintelligence (Oxford: Blackwell Publishing, 2007), pp. 323-324.

${ }^{130}$ Ibid., p. 324.

${ }^{131}$ Jonathan Harrison, 'The Case of Jocasta Jones', Analysis, March 1979.

${ }^{132}$ Robert A. Heinlein, 'All You Zombies', The Magazine of Fantasy and Science Fiction (March 1959), pp. 91-100.
} 


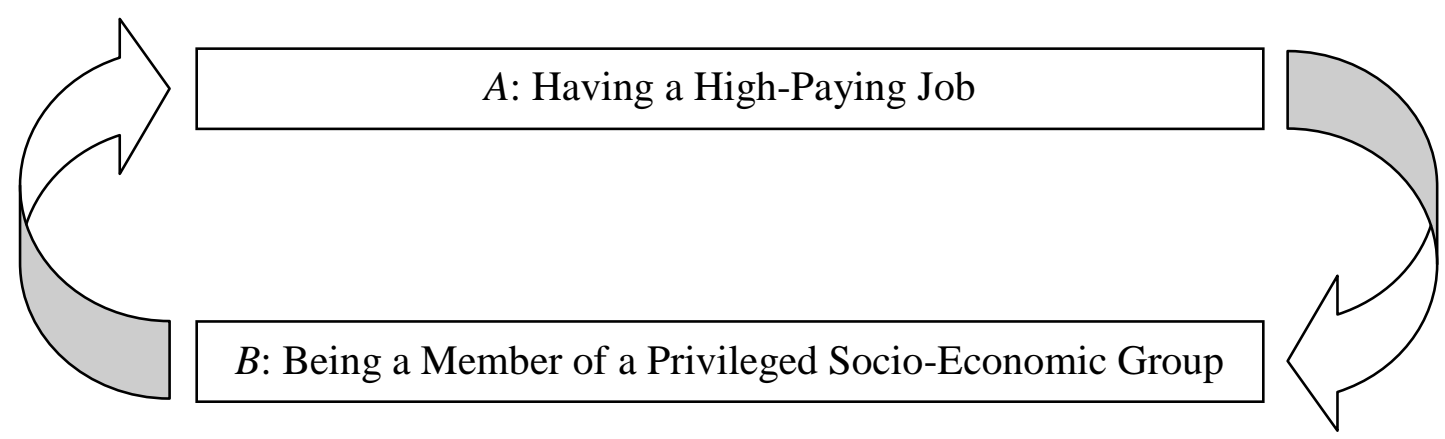

Suppose that these two causal factors are genuinely independent. $A$ describes the income of an individual, while $B$ instead describes the socio-economic position of that same person in terms of their access to particular resources. ${ }^{133} \mathrm{We}$ can also make a persuasive argument for each causal factor being a cause of the other. An individual who is a member of a privileged socio-economic group will have access to a better education, and will therefore have an increased chance of obtaining a career in a highly skilled (and highly paid) profession. Further, an individual who has a high-paying job will have an increased chance of becoming a member of a privileged socio-economic group, as the remuneration they receive will make more resources and opportunities available to them.

Suppose, then, that the following facts are true:

1. The probability of your having a high-paying job if you are a member of a privileged socio-economic group is 0.7 .

2. The probability of your having a high-paying job if you are not a member of a privileged socio-economic group is 0.4 .

3. The probability of your being a member of a privileged socio-economic group if you have a high-paying job is 0.9 .

4. The probability of your being a member of a privileged socio-economic group if you do not have a high-paying job is 0.2 .

These facts can then be stated more succinctly as follows:

1. $\mathrm{p}(A)$ if $B$ is 0.7

\footnotetext{
${ }^{133}$ Here I have in mind things like education and healthcare.
} 
2. $\mathrm{p}(A)$ if $\sim B$ is 0.4

3. $\mathrm{p}(B)$ if $A$ is 0.9

4. $\mathrm{p}(B)$ if $\sim A$ is 0.2

Consider a population of 1000 people, and assume that 200 of them are members of a privileged socio-economic group. If this is so, then $140(0.7 \times 200)$ of those who are members of a privileged socio-economic group will have high-paying jobs, while $60(0.3 \times$ 200) will not. Of those who are not members of a privileged socio-economic group 320 $(0.4 \times 800)$ will have high-paying jobs, while $480(0.6 \times 800)$ will not. Out of the population of 1000 then, 460 individuals will have high-paying jobs, and 540 will not:

\begin{tabular}{|c|c|c|}
\hline & $\begin{array}{c}\text { Have a } \\
\text { High-Paying Job }\end{array}$ & $\begin{array}{c}\text { Do Not Have a } \\
\text { High-Paying Job }\end{array}$ \\
\hline $\begin{array}{l}\text { Members of a Privileged } \\
\text { Socio-Economic Group }\end{array}$ & 140 & 60 \\
\hline $\begin{array}{c}\text { Not Members of a } \\
\text { Privileged } \\
\text { Socio-Economic Group }\end{array}$ & 320 & 480 \\
\hline TOTALS & 460 & 540 \\
\hline
\end{tabular}


But consider what this means for the number of individuals in this society who are members of a privileged socio-economic group. If 460 individuals have high-paying jobs, then $414(0.9 \times 460)$ of those with high-paying jobs will be members of a privileged socioeconomic group, while $46(0.1 \times 460)$ will not. Of those without high-paying jobs, $108(0.2$ $\times 540)$ will be members of a privileged socio-economic group, while $432(0.8 \times 540)$ will not. Out of the population of 1000, then, 522 individuals will be members of a privileged socio-economic group, and 478 will not:

\begin{tabular}{|c|c|c|}
\hline & $\begin{array}{l}\text { Members of a Privileged } \\
\text { Socio-Economic Group }\end{array}$ & $\begin{array}{c}\text { Not Members of a } \\
\text { Privileged } \\
\text { Socio-Economic Group }\end{array}$ \\
\hline $\begin{array}{c}\text { Have a } \\
\text { High-Paying Job }\end{array}$ & 414 & 46 \\
\hline $\begin{array}{c}\text { Do Not Have a } \\
\text { High-Paying Job }\end{array}$ & 108 & 432 \\
\hline TOTALS & 522 & 478 \\
\hline
\end{tabular}

But this goes against the very assumption we made to begin with - that is, that this population contained 200 individuals who were members of a privileged socio-economic 
group. According to Mellor, many probabilistic combinations will result in this sort of contradiction, and these contradictions will arise no matter how many links are in the causal loop. Mellor therefore argues that all causal loops, and thus all backwards time travel journeys, are logically impossible.

\subsection{Responding to Mellor's Second Objection}

Mellor is correct in stating that all effects have chances with and without their causes, and that over time one expects to see the frequency of an event being proportional to its probability. When considering causal loops, however, Mellor takes these rules particularly the second one - to be inviolable. Put simply, Mellor holds that the frequency of an event must be proportional to its probability. Nicholas J.J. Smith explains how probabilistic expectations would go out the window if time travel became an everyday occurrence. ${ }^{134}$ I do not intend to repeat that argument here. Instead, it is enough to note that, by definition, the occurrence of a causal loop requires the occurrence of all its constituent causal factors - regardless of what their individual chances of occurring actually are.

Consider a causal loop containing only two causal factors $(Y)$ and $(Z)$, and suppose that each causal factor has a probability of 0.1 of causing the other factor, That is:

1. $\mathrm{p}(Y)$ if $Z$ is 0.1

2. $\mathrm{p}(Z)$ if $Y$ is 0.1

If each causal factor occurs, then the causal loop - however improbable - will be self-sustaining. Mellor labours under the mistaken assumption that on each 'lap' of the causal loop the chances of causally related events actually occurring leads to an ever decreasing spiral of improbabilistic outcomes. On Mellor's view, then, the fact that $\mathrm{p}(Y)$ if $(Z)=0.1$, and $\mathrm{p}(Z)$ if $(Y)=0.1$, means that $\mathrm{p}(Y)$ if $Z$ if $Y=0.01$. This is not the case however, and to think this way seems to come very close to committing the second-time

\footnotetext{
${ }^{134}$ Nicholas J.J. Smith, 'Bananas Enough for Time Travel?', British Journal for the Philosophy of Science, No. 48 (1997), pp. 363-389.
} 
around fallacy. ${ }^{135}$ If $Y$ causes $Z$, and $Z$ causes $Y$, then this is what occurs. It does not matter how unlikely it is that each of these events causes the other.

Perhaps, however, this criticism of Mellor is somewhat uncharitable - and his argument concerning the inherent probabilistic contradictions of causal loops still holds. If this is so, then I have a much simpler reply to give: namely, the same reply that was given to Mellor's first objection: Backwards time travel does not require causal loops, so our conception of backwards time travel does not require us to conceive of them. This is due to the fact that many (if not most) events are causally unrelated.

To be clear, an example of a causal loop is where $A$ causes $B, B$ causes $C$, and $C$ causes $A$. Such a story can be pictured as follows:

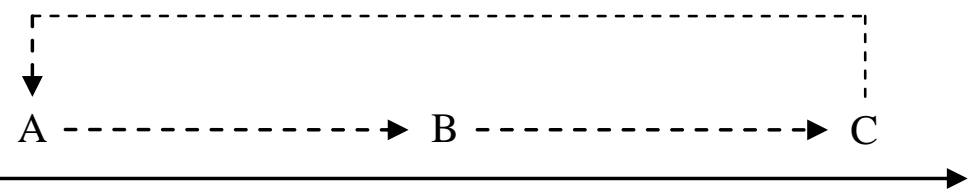

I contend, however, that backwards causation - and, by virtue of this, backwards time travel - does not require us to conceive of causal loops. Instead, our conception of a case of backwards causation only requires us to conceive of a causal arc. A causal arc occurs where an effect merely precedes its cause. An example of a causal arc is where $A$ causes $B$, and $B$ occurs earlier than $A$. Such a story can be pictured as follows:

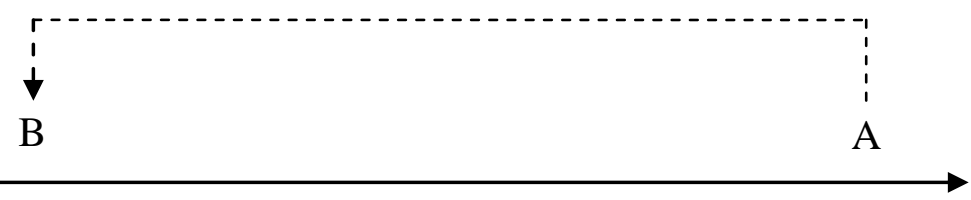

${ }^{135}$ For a full description of this fallacy, see above at p. 12. 
A causal arc will not become a causal loop unless the effect instigates a chain of causal dependence which links up with the initial cause (just as $A, B$, and $C$ do in the earlier diagram).

Our conception of Vincent's backwards time travel journeys only required of us to conceive of causal arcs. That is, Vincent's disappearance at $12.00 \mathrm{pm}$ was a cause of Vincent's appearance at 6.00am. These stories would only contain causal loops if Vincent's arrival in the past somehow affected his departure in the future, and none of Vincent's backwards time travel stories contained such a fact. If this was not explicit, then we could easily include extra facts in the story to make sure that it is, such as having Vincent travel to a remote spatial location during his backwards time travel journey so that he arrives in the past somewhere greatly removed where he will depart. ${ }^{136}$

Our ability to conceive of backwards causation, and thus backwards time travel, only depends on our ability to conceive of causal arcs. For this reason, the logical impossibility of causal loops (if they are in fact logically impossible - a point of which I am not convinced), does not entail the logical impossibility of all cases of backwards time travel. At best, it would merely entail the logical impossibility of certain kinds of backwards time travel stories, namely those containing causal loops.

\section{Conclusion}

Mellor outlines a widely adopted theory of causation - one that defines temporal order as causal order. Such a theory is perfectly compatible with the logical possibility of backwards time travel.

Despite this compatibility, Mellor raises two objections to the logical possibility of backwards time travel. Since conceivability entails possibility, and we can clearly conceive of cases of backwards time travel, Mellor's argument must be flawed in some way. This flaw is located in the fact that Mellor argues from the impossibility of some cases of

\footnotetext{
${ }^{136}$ Bradley Monton explains how backwards time travel can occur without causal loops in Bradley Monton, 'Time Travel Without Causal Loops', The Philosophical Quarterly, Vol. 59, No. 234 (February 2008), pp. 54-67.
} 
backwards time travel to the impossibility of all backwards time travel journeys. Causal loops and paradoxes in which a time traveller kills their own grandfather may very well be logically impossible, but our ability to conceive of backwards time travel in no way necessitates that we conceive of these sorts of situations. Some cases of backwards time travel are impossible. Where Mellor makes his error is in arguing that this means all cases of backwards time travel are impossible. 


\section{Chapter 6: Final Conclusion}

There are many impossible time travel stories: stories that involve time travellers changing the past, killing their younger selves, or creating any number of other paradoxical scenarios. Despite this, there are also many time travel stories that are entirely conceivable. If the conceivability thesis is true, then the conceivability of these stories entails their logical possibility.

All instantaneous forwards time travel journeys are conceivable. Stories in which a time traveller activates his time machine and finds himself instantly transported to some future point in time (just as Marty McFly does when he travels back to the future) are therefore logically possible. The same is true for cases of gradual forwards 'time travel'. Stories in which a traveller activates his machine and finds himself gradually transported to some future point in time (just as the protagonist in H.G. Wells' The Time Machine does) are therefore also logically possible. Unfortunately however, these sorts of conceivable stories are not conceivable time travel stories. This is due to the fact that they fail the time discrepancy requirement for a genuine case of time travel.

The conceivability of backwards time travel journeys is more contentious. It is important, however, to make a distinction between the conceivability of these journeys and the conceivability of certain things that the time traveller might try to do in the past. I have argued that all instantaneous backwards time travel journeys are entirely conceivable. There are plenty of inconceivable things the time traveller might do upon arriving in the past, but this is uninteresting. There are plenty of impossible things any traveller might do upon the conclusion of any sort of journey, but this tells us nothing about the possibility of those journeys. It is conceivable that the time traveller at least gets to the past - and this is all that genuine backwards time travel requires. He must of course travel to some location where he actually arrived in order for the story to be conceivable, but again, this is nothing surprising. It will always be inconceivable for someone to arrive at a location where they do not arrive. This will be true whether that individual is travelling through time, space, or any other sort of dimension. 
Depending on how the story is told, a gradual backwards time travel journey may fail to be conceivable. The time traveller might, for example, collide with his earlier self if he stays stationary and merely reverses his direction in time. This is what is referred to as the Double Occupancy Problem. Despite this, there are many cases of gradual backwards time travel journeys that are conceivable, and one such example was given at the conclusion of Chapter 3. This demonstrates that there is nothing essentially inconsistent about gradual backwards time travel journeys.

I have argued that the conceivability of different kinds of time travel should inform the metaphysical views we choose to adopt. The conceivability of any case of time travel entails the conceivability of travel to other times, so any plausible theory of time must be able to account for this. Views, like presentism, which are commonly held to preclude the logical possibility of time travel must either be modified to allow for its possibility, or abandoned altogether.

I also argued that the conceivability of instantaneous time travel entails the logical possibility of causation at a distance, while the conceivability of backwards time travel entails the logical possibility of backwards causation. Any plausible theory of causation must therefore be able to account for the possibility of these two types of causation.

Of particular concern is the logical possibility of backwards causation, something that many theories of causation - including that put forward by D.H. Mellor - hold to be necessarily contradictory. Mellor gives two arguments against the possibility of backwards causation. Firstly, he focuses on how backwards causation gives rise to impossible scenarios such as the Grandfather Paradox. My reply to this was the same as before however. The Grandfather Paradox is merely an example of something a time traveller might try to do upon arriving in the past. Backwards time travel does not necessarily entail these sorts of occurrences. Secondly, Mellor alleges that the possibility of backwards causation entails the possibility of causal loops, and that these too are contradictory. In reply, I argued that causal loops were not contradictory and that, even if they were, backwards time travel does not necessarily entail their creation. Instead, backwards time travel only requires causal arcs. While the impossibility of causal loops might preclude the possibility of some time travel stories, it does not preclude all of them. 
Many time travel stories - including stories of both backwards and forwards time travel - are conceivable. Further, the conceivability of these stories entails their logical possibility. Our metaphysical views should be made to accommodate this. 


\section{Bibliography}

John Bigelow, 'Time Travel Fiction' in Gerhard Preyer \& Frank Siebelt (eds.), Reality and Humean Supervenience: Essays on the Philosophy of David Lewis (Oxford: Rowman \& Littlefield Publishers, 2001), pp. 57-91.

Craig Bourne, A Future for Presentism (Oxford: Oxford University Press, 2006).

David Chalmers, The Conscious Mind: In Search of a Fundamental Theory (New York: Oxford University Press, 1996).

David Chalmers, 'Does Conceivability Entail Possibility?' in T. Gendler \& J. Hawthorne (eds), Conceivability and Possibility (Oxford: Oxford University Press, 2002), pp. 145200 .

Paul Davies, 'How to Build a Time Machine', Scientific American, Vol. 21, No. 1 (Spring 2012), pp. 24-29.

Phil Dowe, 'The Case for Time Travel', Philosophy, Vol. 75, No. 293 (July 2000), pp. 445-451.

David Deutsch and Michael Lockwood, 'The Quantum Physics of Time Travel', in Susan Schneider (ed.) Science Fiction and Philosophy - From Time Travel to Superintelligence (Oxford: Blackwell Publishing, 2007), pp. 322-334.

William Grey, 'Troubles with Time Travel', in Philosophy, Vol. 74, No. 287 (January 1999), pp. 55-70.

Steven D. Hales, 'No Time Travel for Presentists', Logos \& Episteme I, 2 (2010), pp 353360. 
Jonathan Harrison, ‘The Case of Jocasta Jones', Analysis, March 1979.

Robert A. Heinlein, 'All You Zombies', The Magazine of Fantasy and Science Fiction (March 1959), pp. 91-100.

Simon Keller and Michael Nelson, 'Presentists Should Believe in Time Travel', Australasian Journal of Philosophy, Vol. 79, No. 3 (September 2001), pp. 333-345.

David Lewis, 'Counterfactual Dependence and Time's Arrow', Noûs, Vol. 13, No. 4, Special Issue on Counterfactuals and Laws (November 1979), pp. 455-476.

David Lewis, 'The Paradoxes of Time Travel', Philosophical Papers Volume II (Oxford: Oxford University Press, 1987), pp. 67-80.

Ronald Mallett and Bruce Henderson, Time Traveller - A Scientist's Personal Mission to Make Time Travel a Reality (New York: Basic Books, 2009).

D.H. Mellor, Real Time II (London: Routledge, 1988).

Bradley Monton, 'Presentists can believe in closed timelike curves', Analysis 63.3 (July 2003), pp. 199-202.

Bradley Monton, 'Time Travel Without Causal Loops', The Philosophical Quarterly, Vol. 59, No. 234 (February 2008), pp. 54-67.

Ken Perszyk and Nicholas J.J. Smith, The Paradoxes of Time Travel, presented at Te Papa (National Museum of New Zealand) on 23 August 2001.

Theodore Sider, 'Time Travel, Coincidences and Counterfactuals', Philosophical Studies 110 (2002) pp. 115-138.

Nicholas J.J. Smith, 'Bananas Enough for Time Travel?', British Journal for the Philosophy of Science, No. 48 (1997), pp. 363-389. 
Paul Tidman, 'Conceivability as a Test for Possibility', American Philosophical Quarterly, Vol. 31, No. 4 (October 1994), pp. 297-309.

H.G. Wells, The Time Machine (London: Penguin Group, 2005).

Dean W. Zimmerman, 'The A-Theory of Time, the B-Theory of Time, and 'Taking Tense Seriously", Dialectica Vol. 59, No. 4 (2005), pp. 401-457.

Back to the Future, Dir. Robert Zemeckis, Universal Pictures, 1985.

Los Cronocrímenes (Timecrimes), Dir. Nacho Vigalondo, Karbo Vantas Entertainment, 2007.

Primer, Dir. Shane Carruth, THINKFilm, 2004.

Star Wars: Episode IV - A New Hope, Dir. George Lucas, Lucasfilm and Twentieth Century Fox Film Corporation, 1977.

'Blink', Doctor Who, Season 3, Episode 10, Dir. Hettie MacDonald, British Broadcasting Corporation (BBC), 2007.

'Space Pilot 3000', Futurama, Dirs. Rich Moore and Gregg Vanzo, The Curiosity Company and Twentieth Century Fox, 1999. 